NISTIR 8254

\title{
Ampoules for Radioactivity Standard Reference Materials ${ }^{\mathrm{TM}}$
}

Ronald Collé

This publication is available free of charge from:

https://doi.org/10.6028/NIST.IR.8254

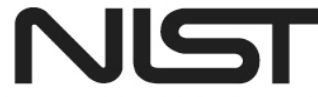

National Institute of Standards and Technology U.S. Department of Commerce 
NISTIR 8254

\title{
Ampoules for Radioactivity Standard Reference Materials ${ }^{\mathrm{TM}}$
}

\author{
Ronald Collé \\ Radiation Physics Division \\ Physical Measurement Laboratory
}

This publication is available free of charge from:

https://doi.org/10.6028/NIST.IR.8254

August 2019

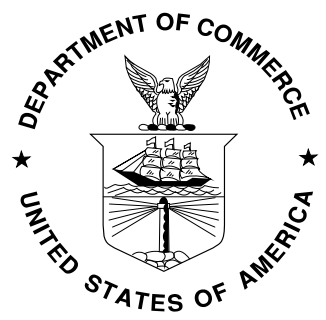

U.S. Department of Commerce Wilbur L. Ross, Jr., Secretary

National Institute of Standards and Technology Walter Copan, NIST Director and Undersecretary of Commerce for Standards and Technology 
Certain commercial entities, equipment, or materials may be identified in this document in order to describe an experimental procedure or concept adequately. Such identification is not intended to imply recommendation or endorsement by the National Institute of Standards and Technology, nor is it intended to imply that the entities, materials, or equipment are necessarily the best available for the purpose.

National Institute of Standards and Technology Interagency or Internal Report 8254 Natl. Inst. Stand. Technol. Interag. Intern. Rep. 8254, 32 pages (August 2019)

This publication is available free of charge from: https://doi.org/10.6028/NIST.IR.8254 


\section{TABLE OF CONTENTS}

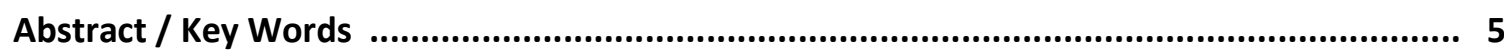

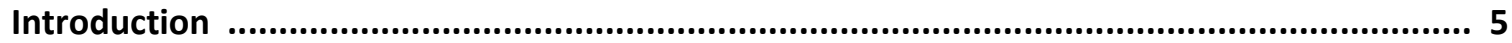

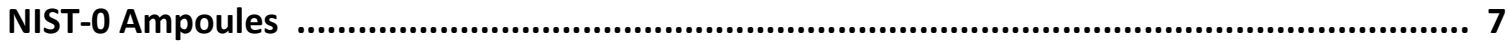

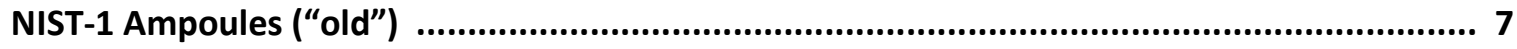

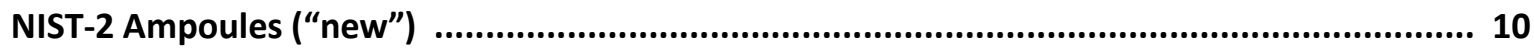

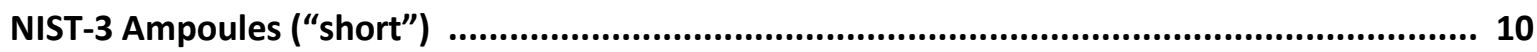

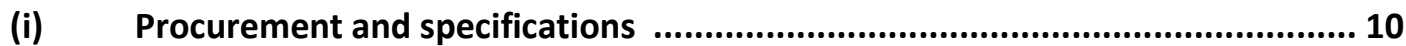

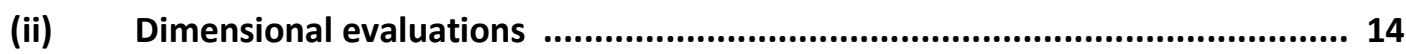

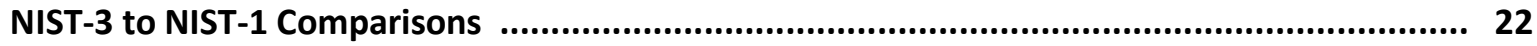

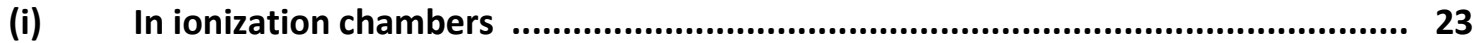

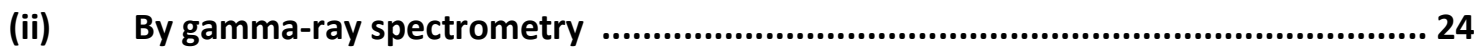

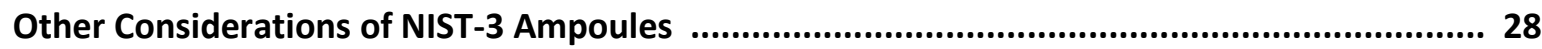

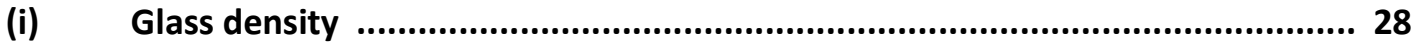

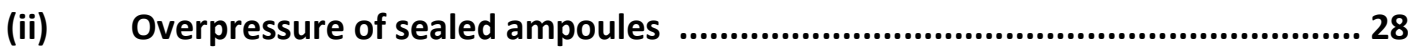

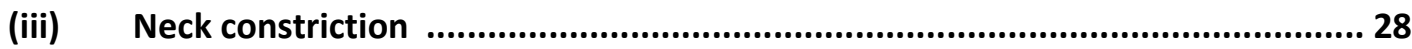

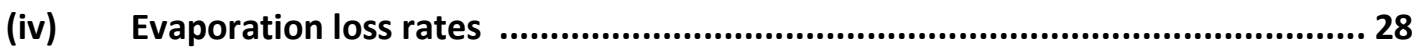

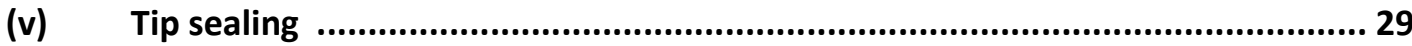

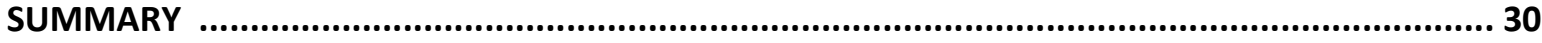

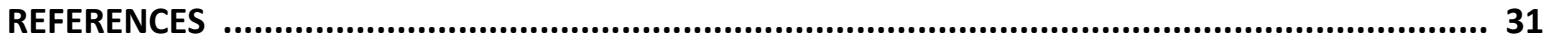

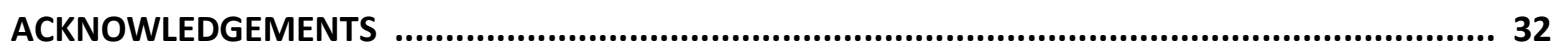

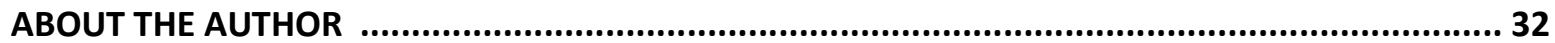




\title{
Ampoules for Radioactivity Standard Reference Materials ${ }^{\mathrm{TM}}$
}

\author{
R. Collé \\ National Institute of Standards and Technology \\ Gaithersburg, MD 20899-8462 USA
}

\begin{abstract}
Standard-sized ampoules for radioactive solution standards have been employed by the National Institute of Standards and Technology (NIST) for nearly the past 70 years. This report briefly summarizes the origins and history of the five different batches of ampoules that have been used, including details on the procurement and testing of the recent batch of replacement ampoules in 2018.
\end{abstract}

KEY WORDS: Gamma-ray spectrometry, Glass ampoules, Ionization chamber, SRM ${ }^{\mathrm{TM}}$, Standards, Radioactivity

\section{INTRODUCTION}

The National Institute of Standards and Technology (NIST) is the national standards laboratory for the USA. Within the NIST Physical Measurement Laboratory, the Radioactivity Group of the Radiation Physics Division provides Standard Reference Materials ${ }^{\mathrm{TM}}$ (SRM) and calibration sources of radioactive material for a wide variety of applied science disciplines, including those for environmental radiation surveillance, nuclear power, homeland security, nuclear forensics, and both diagnostic and therapeutic nuclear medicine. A component part of the measurement services provided by the NIST Radioactivity Group is the use of standard ampoules for external measurements of photonic emission by either spectrometry (Pibida, et al., 2007; Pibida, et al., 2006; and references therein) or ionization currents (Fitzgerald, 2012 and references therein). In addition, many users of NIST SRMs and calibration services use standards that rely on these ampoules for direct measurements in fixed geometries. Such standard ampoules have been in use by the NIST Radioactivity Group for nearly 70 years, i.e., since c. 1950. Their use is intended to provide fixed solid angle geometries, and reproducibility of this geometry over many years. The standard geometry used by NIST consists of $5 \mathrm{~mL}$ of a radioactive solution in a flame-sealed, $5 \mathrm{~mL}$, borosilicate glass ampoule.

In 1976, an International Reference System (SIR) under the auspices of the Bureau International des Poids et Mesures (BIPM) was established for activity measurements of gamma-ray-emitting radionuclides, making it possible for national metrology institutes to check the reliability of their activity measurements by comparison with other laboratories world-wide (Ratel, 2007). The then-current NIST standard ampoule was chosen for use with the SIR, and NIST (then NBS, the National Bureau of Standards) distributed approximately 70000 of these ampoules to BIPM and to other major radionuclidic metrology laboratories throughout the world. As of 2019, these NIST / BIPM standard ampoules are still in use with the SIR for activity.

Although radioactive solution standards from NBS/NIST had been put up in flame-sealed glass ampoules prior to about 1950, particularly the cone-shaped ampoules used for solutions of ${ }^{226} \mathrm{Ra}$ and other naturally-occurring, primordial radionuclides that decay primarily by alpha emission, there had been scant need to adopt a standard ampoule geometry. With the advent of nuclear reactors and particle accelerators following World War II to 
produce many artificially-made radionuclides for many applications, it became practical to adopt a standard source configuration, particularly for external measurements of photons for nuclides that decay by beta emission.

Table 1 summarizes the five different batches of $5 \mathrm{~mL}$ ampoules that have been used by the NIST Radioactivity Group for measurements and dissemination of SRMs. It is important to recognize that the NIST-2 ampoules, although used for alpha-emitting and some pure beta-emitting SRMs, were never intended for external measurements of photonic emission by either spectrometry or ionization currents.

Table 1. Tabular summary of information on the five different batches of $5 \mathrm{~mL}$ ampoules used by the NIST Radioactivity Group for measurements and dissemination of SRMs. Dimensional uncertainties are $95 \%$ confidence limits for the distributions. Values without uncertainties are nominal. Dimensions for the NIST-1 ampoule were made by BIPM (Rytz, 1978).

\begin{tabular}{|c|c|c|c|c|c|}
\hline $\begin{array}{c}\text { Ampoule } \\
\text { designation }\end{array}$ & $\begin{array}{c}\text { Acquisition } \\
\text { date }\end{array}$ & Supplier / source & $\begin{array}{c}\text { Nominal } \\
\text { height, } \\
\text { unsealed } \\
(\mathrm{mm})\end{array}$ & $\begin{array}{c}\text { Body outer } \\
\text { diameter } \\
D(\mathrm{~mm})\end{array}$ & $\begin{array}{c}\text { Body wall } \\
\text { thickness } W \\
(\mathrm{~mm})\end{array}$ \\
\hline NIST-0 & $\begin{array}{c}\text { c. } 1950 \\
\text { c. } 1965\end{array}$ & $\begin{array}{c}\text { Stock item } \\
\text { Kimble Glass }\end{array}$ & $\begin{array}{c}82 \\
84\end{array}$ & 16.1 & 0.6 \\
\hline NIST-1 & 1976 & $\begin{array}{c}\text { Custom made to specs } \\
\text { Kimble Glass }\end{array}$ & 88 & $16.44 \pm 0.18$ & $0.642 \pm 0.012$ \\
\hline NIST-2 & 2006 & $\begin{array}{c}\text { Stock item } \\
\text { Wheaton Cryule } \\
\text { cryogenic ampoule }\end{array}$ & 98 & 16.2 & 1.1 \\
\hline NIST-3 & 2018 & $\begin{array}{c}\text { Custom made to specs } \\
\text { DWK }\end{array}$ & 75 & $16.193 \pm 0.084$ & $0.603 \pm 0.012$ \\
\hline
\end{tabular}

Figure 1. The five different $5 \mathrm{~mL}$ ampoules used by NBS / NIST. (photo credit: R. Fitzgerald, 2019)

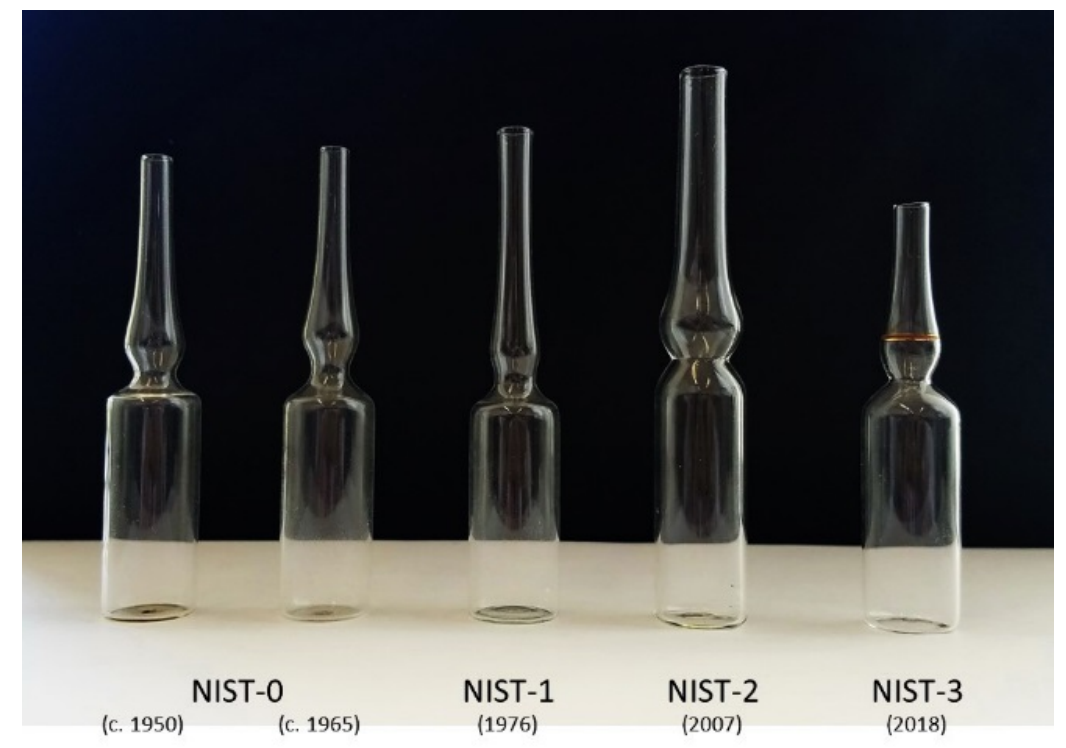

Page 6 of 32 


\section{NIST-0 AMPOULES}

The first two batches of standard ampoules (herein called NIST-0) were obtained in or around 1950 and 1965. They are believed to have been manufactured by Kimble Glass ${ }^{1}$ and were purchased from chemical supply vendors as stock items. Dimensions for these ampoules are not well documented. Based on the requested specifications for the NIST-1 ampoules that were intended to match the 1965 NIST-0 batch, it is believed that the wall thickness was probably about $0.6 \mathrm{~mm}$. These NIST-0 ampoules were also said to contain a high Ba element content of about 2.25 \% (in unstated units), though the origin of this is unknown and undocumented.

\section{NIST-1 AMPOULES ("old")}

In the decade following 1965, many more calibrations of secondary instruments from primary standardization were made using the NIST-0 ampoules, therefore it was desired that a replacement batch (NIST-1) closely match the existing ones. NIST arranged to have Kimble Glass custom fabricate a batch of ampoules that would match the 1965 NIST-0 ampoules. These replacement ampoules were also intended to serve as an "international standard ampoule" to be used by BIPM and other laboratories for the SIR.

Specifications requested by NIST included (Collé, 1976):

Custom made ampoule of $5 \mathrm{~mL}$ capacity

Unscored and unbonded Type I glass

Barium content should not exceed $2.5 \%$, but $2.25 \%$ would be preferable (unspecified \% units)

Lead oxide should be less than $0.02 \%$

Any other heavy metals in only trace quantities

All ampoules should be made from same molten glass batch

Boxes containing the ampoules should be marked as to order of production

Body outside diameter in range $16.3 \mathrm{~mm}$ to $16.7 \mathrm{~mm}$

Body wall of $0.60 \pm 0.04 \mathrm{~mm}$

Body straight length of $37 \mathrm{~mm} \pm 1 \mathrm{~mm}$

Flat bottom

It is believed that the high Ba content was requested to match that said to be contained in the 1965 NIST-0 ampoules. As before, the units for the percentages were not specified.

Kimble Glass (King of Prussia, PA USA) proposed to provide the ampoules with the following dimensions, as given in Figure 2, in accepting all other conditions of the contract order (Collé, 1976):

Body outside diameter of "16.3 $\mathrm{mm}$ to $16.70 \mathrm{~mm}$ "

Wall thickness $=0.60 \mathrm{~mm}$

Body length $=(37 \pm 1) \mathrm{mm}$

Maximum bottom push-up $=1.6 \mathrm{~mm}$

\footnotetext{
${ }^{1}$ Certain commercial equipment, instruments, and materials are identified in this paper to foster understanding. Such identification does not imply recommendation or endorsement by NIST, nor does it imply that the materials and/or equipment are the best available for the purpose.
} 
An order for 144000 "special" 5 mL ampoules (called KG 12011S) was placed with Kimble Glass "to supply not only NBS, but other standardizing laboratories throughout the world, with the same kind of container in order to improve the International Radioactivity Measurement System." (Collé, 1976). The ampoules were received in June 1976 and compared to the NIST-0 ampoules then currently in use. The order was not accepted because it was said that the ampoules did not meet two specifications (Collé, 1976).

1. "Boxes containing the ampoules were not marked as to order of production. It is important to know this in order to be able to check for possible changes in chemical composition."

2. "The bottoms of the ampoules are not flat; they have excess glass nodules. It is important to have as uniform a surface as possible to avoid non-uniform photon absorption. "

In conclusion, Kimble Glass was informed: "We cannot accept these as international standard ampoules." (Collé, 1976).

In August 1976, Kimble Glass accepted the return of this batch of ampoules and agreed to provide a new batch. Instructions from Kimble Glass sales management to their manufacturing plant stated (Collé, 1976):

"NOTE: SPECIFICATIONS TIGHTER THAN STANDARD 5 ML AMPULS."

“NOTE: BOXES CONTAINING AMPULS SHOULD BE MARKED WITH DATE OF MANUFACTURE AND SHIFT NUMBER" (with implied assumption that all ampoules would be made on the same machine). The capitalized text was that provided by Kimble Glass to NBS (Collé, 1976).

Figure 2. Schematic of NIST-1 ampoule dimensions as provided by Kimble Glass and proposed for production in 1976.

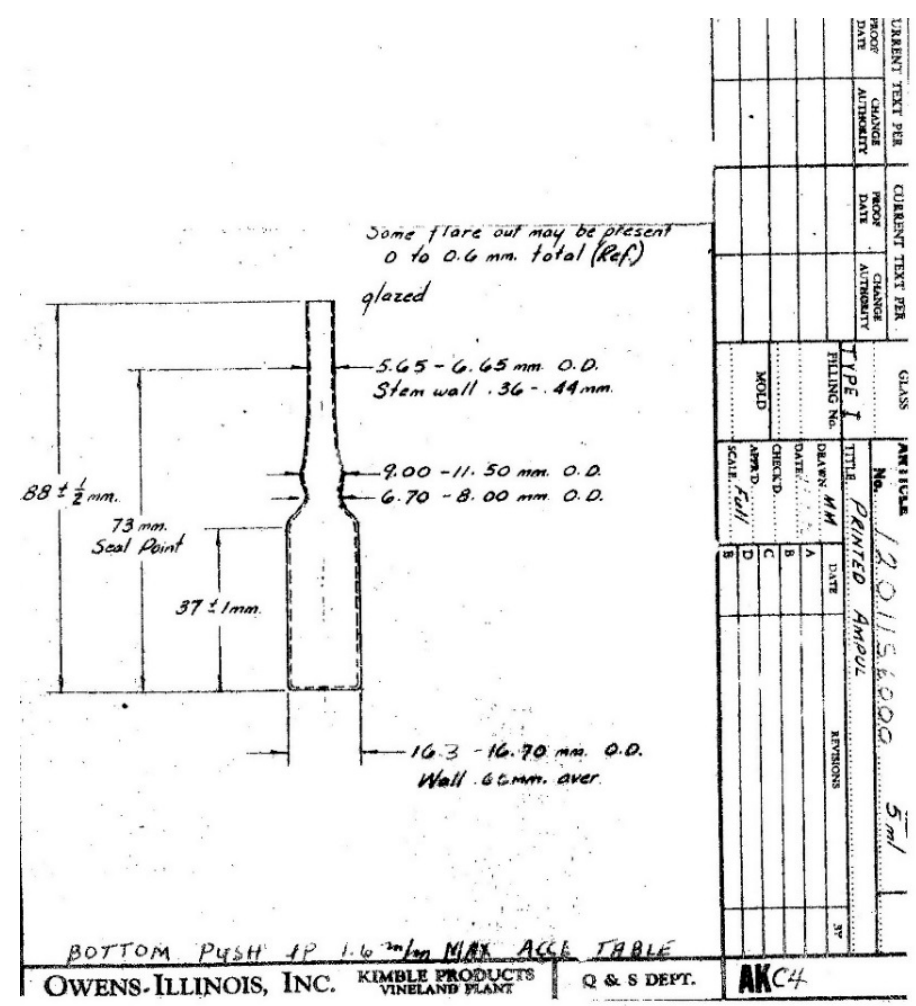


In October 1976, Kimble Glass informed NBS that they completed the production run for the new requested batch, but that they only have approximately 130000 ampoules (of the requested 144000 order) because of "waste" (Collé, 1976). They did not think it advisable to do another production run for only 14000 ampoules, indicating they would also need to use new glass. NBS accepted the short order, on condition of a per ampoule cost adjustment. Although NBS had requested that Kimble Glass ship a few representative samples for evaluation after a new batch was made and before shipping the entire order, Kimble Glass informed NBS on 10 October 1976 that the new batch was already shipped, indicating that they are "confident that the new batch is as good as" the 1965 NIST-0 ampoules (Collé, 1976). They noted that in order to meet the "flat bottom" specification, the ampoules were made by a slower machining process of "one out - instead of two at a time, bottom to bottom" (Collé, 1976), and that periodic visual checks were made throughout the production run. They also indicated that if NBS was not satisfied, they would "not accept a return" of the ampoules and that "no other effort" would be made to provide another batch that meets specifications (Collé, 1976).

The new batch was accepted and is now designated as NIST-1 ampoules. The shipment consisted of 37 large boxes, each containing 24 inner cartons with 144 ampoules. One box contained only 9 cartons. In total 125712 ampoules were received at a cost of $\$ 0.03025$ per ampoule in 1976 USD (\$0.13 per ampoule in 2017 USD). Each box was identified by a sequence of digits that indicated production date, shift number, machine (all identical), and inspector. For inspection and sampling purposes, NBS/NIST numbered each of the 37 boxes and removed one smaller 144-ampoule carton from each level of each box. Four ampoules were randomly selected from each of the 145 sampled cartons for subsequent testing and evaluation. Over the course of the following year, relative ionization chamber measurements were made to directly compare the new NIST-1 ampoules to the 1965 NIST-0 ampoules using radioactive solutions of ${ }^{203} \mathrm{Hg},{ }^{59} \mathrm{Fe},{ }^{109} \mathrm{Cd},{ }^{137} \mathrm{Cs},{ }^{99} \mathrm{Mo},{ }^{51} \mathrm{Cr}$, ${ }^{99 \mathrm{~m}} \mathrm{Tc}$, and ${ }^{111} \mathrm{In}$. Over 55 separate trials were conducted using ampoules from 18 of the 37 boxes (74 separate cartons). No statistically significant differences in ionization current response from identical solutions contained in the NIST0 and NIST-1 ampoules for any radionuclides tested (Collé, 1976) were found. Similarly, no systemic trends in ionization current response for any given radionuclide with ampoule production order were apparent (Collé, 1976). Alas, the original records for these comparisons cannot be located in NIST / NBS files (Collé, 2018).

As noted above, approximately 70000 NIST-1 ampoules were made available to BIPM and other national standardizing laboratories in 1977, and in following years. BIPM will still provide limited numbers of these ampoules to laboratories that wish to participate in the SIR. It is unknown when BIPM will need to find a replacement for the $>40$ year old ampoules for continuance of the SIR.

No evidence can be found that any dimensional measurements were made on the NIST-1 ampoules at the time they were acquired. Personal recollections (Collé, 1976; Collé, 2018) support this view. For many years, up to including today, the NIST website (NIST, 2019) and some SRM Certificates cited ampoule dimensions that appear to only be based on the specifications given by Kimble Glass in their 1976 proposal (Figure 2), with the outer diameter taken from the range given and with the uncertainty on the wall thickness of unknown origin. BIPM (Rytz, 1978), however, on receipt of some of the NIST-1 ampoules, made dimensional measurements of 
the body wall inner diameter and wall thickness, as given in Table 1, and the effect of the dimensional tolerances on ionization current uncertainty.

\section{NIST-2 Ampoules ("new")}

In 2007, the NIST Radioactivity SRM Co-cordinators decided that there was no longer a need or much merit in continuing to put up many of the SRMs in NIST-1 ampoules. In part, their decision was driven by several facts:

1. Many of the disseminated SRMs were not calibrated by external photon measurements in fixed geometries (mainly nuclides decaying by alpha emission or pure beta decay and electron capture).

2. The supply of NIST-1 ampoules was not un-exhaustible and that the remaining ones should be preserved for necessary uses, e.g., for SRMs calibrated by ionization current measurements

3. It was becoming increasingly difficult and labor intensive to adequately clean the 30 year old NIST-1 ampoules because of poor storage conditions in their original cardboard cartons over many years, and the natural aging of glass.

As a result, NIST decided to use different ampoules for those SRMs not calibrated by measurements of photonic emission. It was desired that these ampoules be physically different and distinguished by simple visual observation from the existing NIST-1 ampoules so that the two would never be confused. It was also desired that these ampoules be commercially available as stock items so that only limited quantities needed to be purchased. Cryule cryogenic ampoules from Wheaton Glass (Milville, NJ USA), herein called NIST-2, were chosen. They are heavier, with decidedly greater height and wall thickness, and are impossible to confuse with NIST-1 ampoules (see Figure 3).

Figure 3. Comparison of NIST-1 (on left) and NIST-2 (on right) ampoules, showing the vast differences in size. (photo credit: L. Laureano-Perez, 2017)

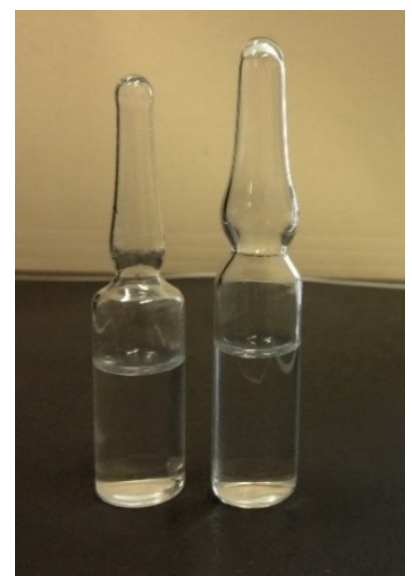

\section{NIST-3 Ampoules ("short")}

\section{(i) Procurement and specifications}

In 2018, the NIST Radioactivity Group sought to acquire a new batch of custom-made ampoules to eventually replace NIST-1. These ampoules were intended to be used like the NIST-1 ampoules for calibrations by external photon measurements and for all Radioactivity SRMs. At the same time, the Radioactivity Group was 
investigating an alternative flame sealing procedure to that currently used. It was becoming increasingly troublesome and difficult for current lab workers to produce large numbers of SRM units by the excess-glassremoval sealing technique with the Collé-Cavallo manual sealer (c. 1975). A more automatic sealing procedure was sought.

To this end, the SRM program of the Radioactivity Group purchased a bench-top sized, fully automatic ampoule sealer, viz., Ampulmatic-10 from Biosciences, Inc. (Allentown, PA USA). This sealer utilizes tip sealing with a propane / oxygen flame rather than the procedure of removing excess glass as performed with the ColléCavallo manual sealer. However, tip sealing with ampoules of height $88 \mathrm{~mm}$ (like NIST-1) would result in sealed ampoules too tall to fit into the NIST ionization chamber holders that have been in use since the 1950s and would also not fit in the currently used SRM packaging containers used for shipments.

NIST, therefore, contracted to procure ampoules of shorter height $(75 \mathrm{~mm})$ to facilitate automatic tip sealing and with wall body outer diameter and wall thickness to closely match NIST-1 ampoules. Figure 4 shows a schematic of the requested dimensional requirements.

Figure 4. Schematic of NIST-3 ampoule dimensions as requested by NIST in 2018.

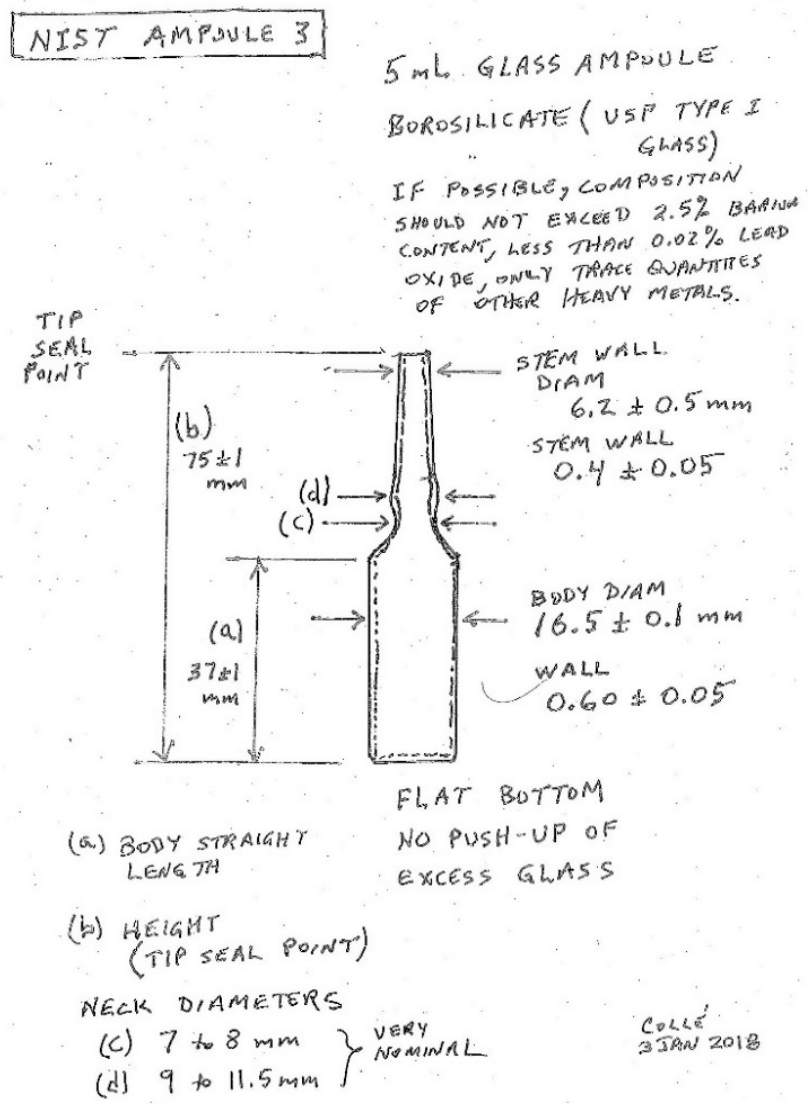

Page 11 of 32 
Additional specifications requested by NIST included (Collé, 2018).

- Custom-made ampoules of $5 \mathrm{~mL}$ capacity

- Ampoules shall be fabricated from USP Type I borosilicate glass.

- Ampoules shall be clear, unscored, and contain a colored identification ring.

- Elemental composition (in mass percentage) of the glass shall be provided and must have a barium content of less than $2.5 \%$, less than $0.2 \%$ lead oxide, and only trace quantities of other heavy metals

- Ampoule dimensions shall be:

o Height: $(75 \pm 1) \mathrm{mm}$

o Straight length of body: $(37 \pm 1) \mathrm{mm}$

o Diameter of body: $(16.5 \pm 0.1) \mathrm{mm}$

0 Wall thickness of body: $(0.60 \pm 0.05) \mathrm{mm}$

o Neck diameters (as group), not critical at about $7 \mathrm{~mm}$ to $8 \mathrm{~mm}$ and $9 \mathrm{~mm}$ to $11.5 \mathrm{~mm}$

o Stem wall diameter at opening: $(6.2 \pm 0.5) \mathrm{mm}$, some minor flare can be present,

o Stem wall thickness: $(0.40 \pm 0.05) \mathrm{mm}$

- Ampoules shall have flat bottom, with glass push-up of less than $1 \mathrm{~mm}$

- All ampoules shall be made from the same batch of molten glass or glass tubing

- Boxes containing the ampoules shall be marked or numbered as to order of production.

Even with global solicitation, the principal glass ampoule manufacturer in the USA, Duran, Wheaton, Kimble (DWK, Millville, NJ), submitted the only proposal to the solicitation and required a minimum order of 40000 ampoules. DWK, through Biosciences, Inc. as vendor, offered to fabricate the ampoules with the dimensional specifications given in Figure 5.

Figure 5. Schematic of NIST-3 ampoule dimensions as provided by DWK and proposed for production in 2018.

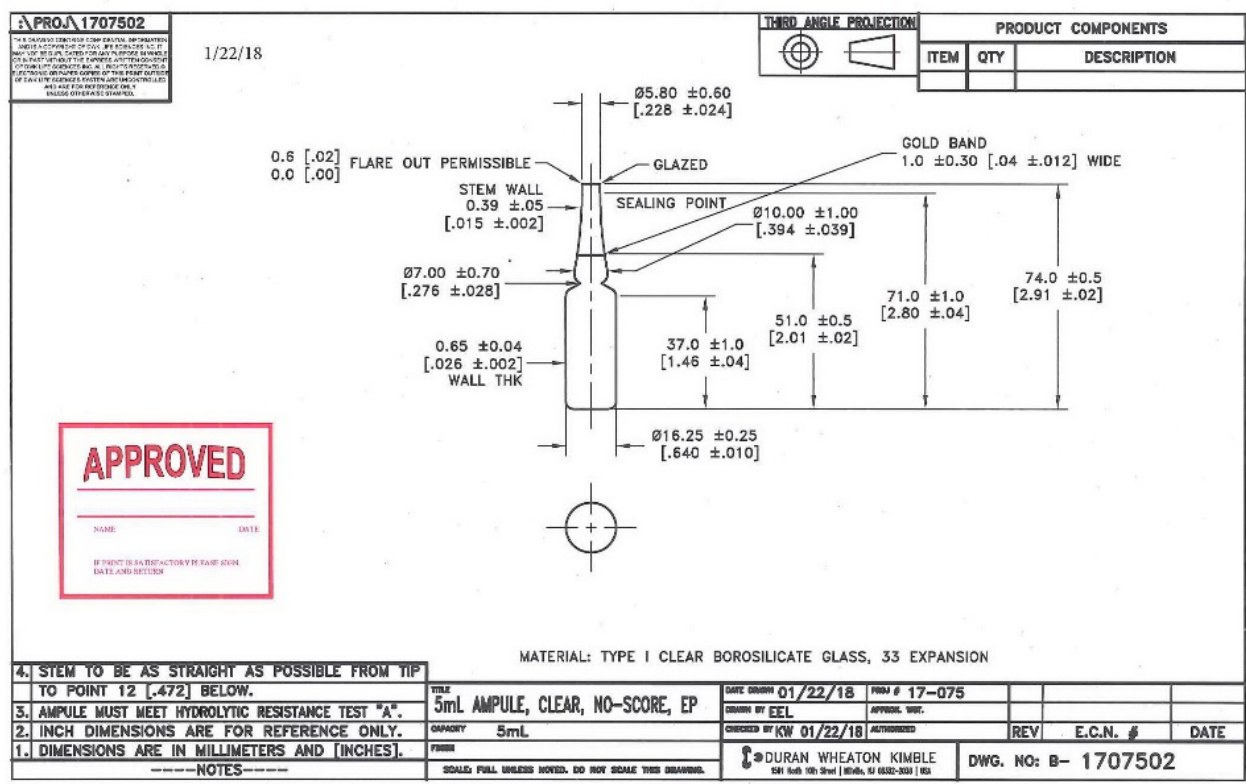

Page 12 of 32 
The chemical composition of the USP Type 1 borosilicate glass used to fabricate the NIST-3 ampoules, as provided by DWK through Biosciences, is given in Table 2 (Collé, 2018). Allowable limits on the extractable hazardous elements for USP Type 1 borosilicate glass containers are given in Table 3. Elemental composition for the principal elements in the NIST-3 ampoules (from the data given in Table 2) is given in Table 4.

Table 2. Chemical analysis of the USP Type I borosilicate glass used to fabricate the NIST-3 ampoules.

\begin{tabular}{|c|c|}
\hline $\begin{array}{c}\text { Molecular } \\
\text { component }\end{array}$ & $\begin{array}{c}\text { Percentage by mass } \\
\text { (typical average) }\end{array}$ \\
\hline $\mathrm{SiO}_{2}$ & 79.5 \\
$\mathrm{~B}_{2} \mathrm{O}_{3}$ & 13.5 \\
$\mathrm{Na}_{2} \mathrm{O}$ & 4.1 \\
$\mathrm{Al}_{2} \mathrm{O}_{3}$ & 2.5 \\
$\mathrm{~K}_{2} \mathrm{O}$ & $<0.1$ \\
$\mathrm{CaO}$ & $<0.01$ \\
$\mathrm{BaO}$ & $<0.01$ \\
$\mathrm{CeO}_{2}$ & $<0.01$ \\
Minors & $<0.1$ \\
\hline
\end{tabular}

Table 3. Allowable limits on the extractable hazardous elements (of atomic number $Z$ ) in USP Type I borosilicate glass containers.

\begin{tabular}{|c|c|c|c|}
\hline Element & $Z$ & $\begin{array}{c}\text { Content limit } \\
\text { (in ppm) }{ }^{\mathrm{a}}\end{array}$ & $\begin{array}{r}\text { Extractable limit } \\
\text { (in ppm) }\end{array}$ \\
\hline $\mathrm{As}$ & 33 & $<2$ & $<0.01$ \\
$\mathrm{Cd}$ & 48 & $<2$ & $<0.01$ \\
$\mathrm{~Pb}$ & 82 & $<2$ & $<0.01$ \\
$\mathrm{Hg}$ & 80 & $<2$ & $<0.01$ \\
$\mathrm{Cr}$ & 24 & $<2^{\mathrm{b}}$ & $<0.01$ \\
\hline \multicolumn{3}{|c|}{$\mathrm{apm}=\mu \mathrm{g} / \mathrm{g}$ b as $\mathrm{Cr}(\mathrm{VI})$} \\
\hline
\end{tabular}

Table 4. Elemental composition (in mole percentage) for the principal elements (of atomic number $Z$ ) in the NIST-3 ampoules, as calculated from the chemical composition data given in Table 2.

\begin{tabular}{|c|c|c|}
\hline Element & $Z$ & Mole percentage \\
\hline $\mathrm{B}$ & 5 & 7.36 \\
$\mathrm{O}$ & 8 & 64.01 \\
$\mathrm{Na}$ & 11 & 2.51 \\
$\mathrm{Al}$ & 13 & 0.93 \\
$\mathrm{Si}$ & 14 & 25.12 \\
$\mathrm{~K}$ & 19 & $<0.04$ \\
\hline
\end{tabular}


The NIST-3 ampoules were ordered in April 2018 and delivered in August 2018. The shipment was identified as "special cut stem amp, Batch 32.231/18" (Collé, 2018) and consisted of 137 boxes, each containing 293 ampoules. In total 40101 ampoules were received at a cost of $\$ 0.2487$ per ampoule (in 2018 USD). Figure 6 shows the scheme used to inspect and sample the batch. Each of the 137 boxes were opened and cursorily examined for physical damage. Three ampoules from each box were randomly selected, and three measurements of the outer diameter of each selected ampoule's body wall were made. An additional ampoule from twenty of the 137 boxes, chosen from a uniform 1 to 137 random number set, were also sampled for subsequent inner diameter and wall thickness measurements. All dimensional measurements were made with an electronic digital caliper whose calibration was checked with gauge blocks at $0.5 \mathrm{~mm}, 1 \mathrm{~mm}, 2 \mathrm{~mm}, 5 \mathrm{~mm}$, $10 \mathrm{~mm}$, and $20 \mathrm{~mm}$.

\section{(ii) Dimensional evaluations}

Let us define critical ampoule dimensions in terms of direct caliper measurements of body outer diameter $(D)$, wall thickness $(W)$, body inner diameter $(S)$, with a derived estimate of wall thickness of $\omega=(D-S) / 2$ that can be compared to direct measurements of $W$. Statistical analyses on the dimensional measurements were performed largely using DataPlot eFit applications (NIST, 2019b).

Figure 6. Experimental design scheme for inspecting and sampling the NIST-3 ampoule shipment.

NIST-3 Ampoules

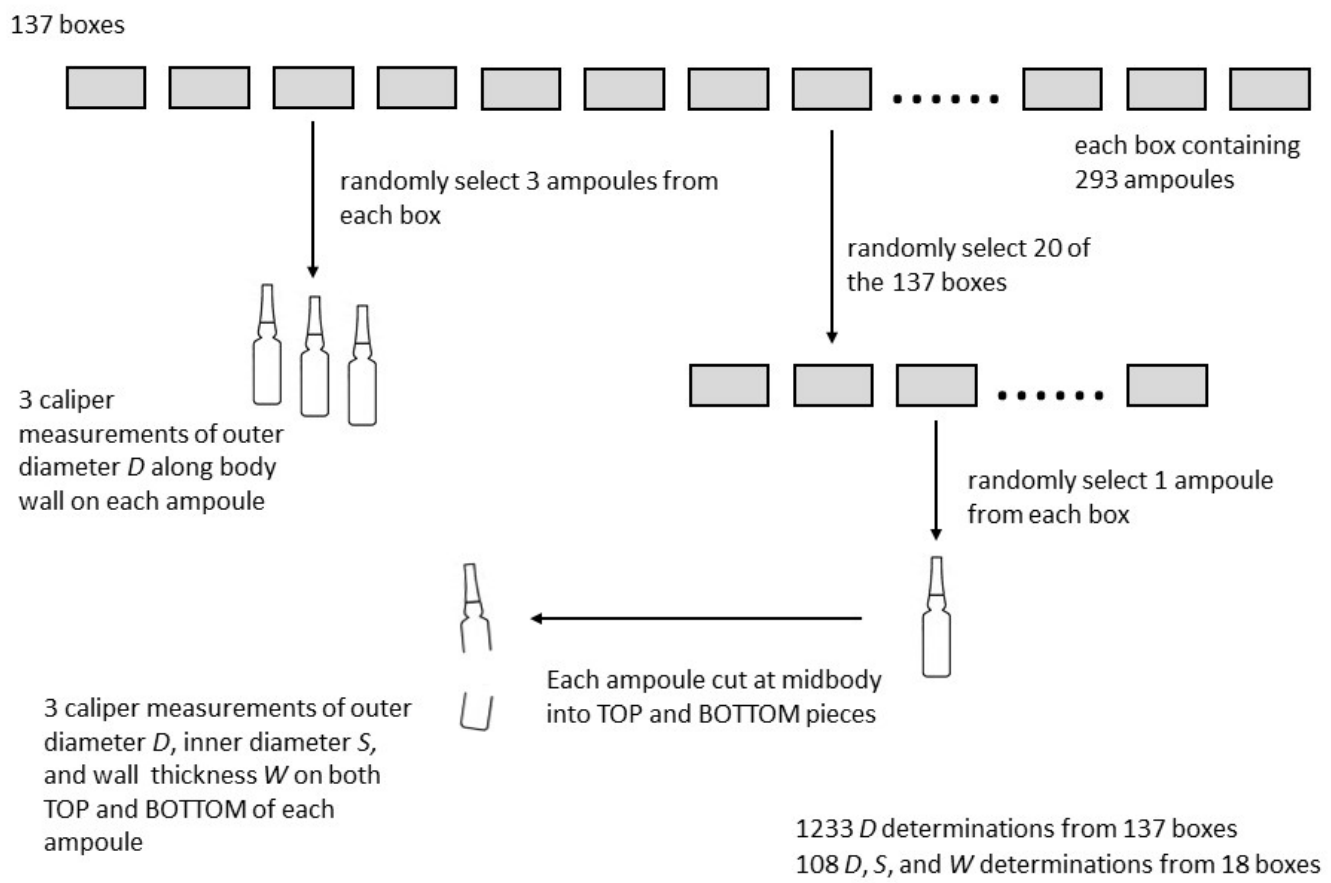


Data for the outer diameter measurements on the sampled ampoules as a function of production order box number are given in Figure 7. The mean diameter, based on three measurements along the length of the ampoule body on each of three ampoules randomly selected from 137 boxes (1233 individual measurements in all), obtained was $16.193 \mathrm{~mm}$, with a standard deviation of the mean of $0.002 \mathrm{~mm}$ for the $n=137$ averages and a $95 \%$ confidence interval on the mean of $\pm 0.005 \mathrm{~mm}$ and a $95 \%$ confidence interval on the distribution of $\pm 0.054 \mathrm{~mm}$. A normal distribution fits the data. We may, of interest, note that exactly 7 of 137 values lie outside (or 130/137 = 0.949 lie inside) the $95 \%$ confidence limits, as seen in Figure 7.

The range for the three $D$ measurements on each ampoule is also of curious interest. The range distribution for all measured 411 ampoules is shown in Figure 8. Although it may on first appearance look like a lognormal distribution, it is not. In fact, a $\chi^{2}$ distribution fits the data. Perhaps this should not be too surprising since the range is a measure of dispersion, as is the variance, and variances are $\chi^{2}$ distributed.

Figure 7. Outer body diameter $D$ for the NIST-3 ampoules as a function of production order box number. Each datum represents the average of three measurements along the height of the body wall on 411 sampled ampoules. The solid and dashed lines correspond, respectively, to the mean value of $D=16.193 \mathrm{~mm}$ and the $95 \%$ confidence limits on the distribution of values.

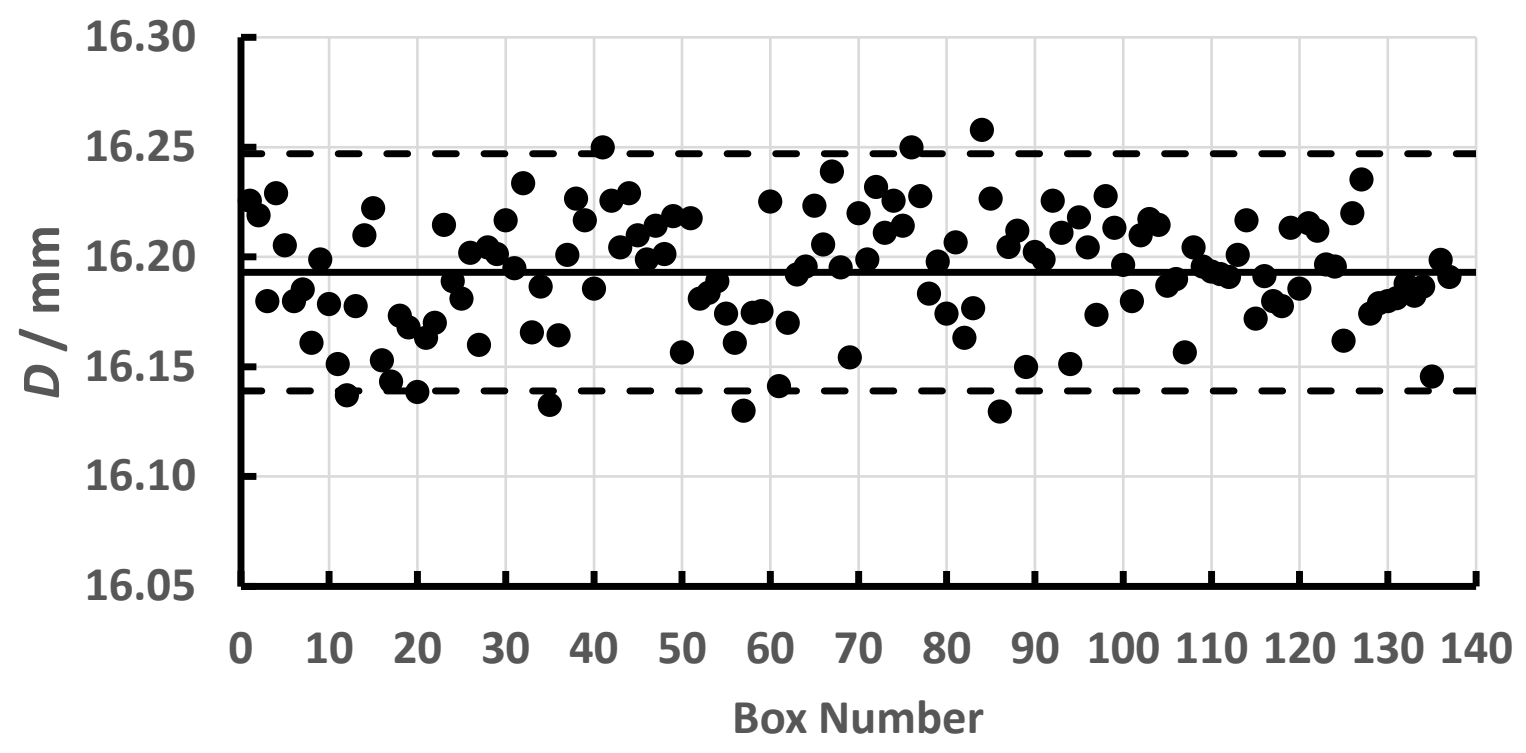

Caliper measurements of outer body diameter $D$, inner body diameter $S$, and wall thickness $W$ as a function of box number were also made on 18 of the ampoules individually selected from the 20 randomly selected boxes (see Figure 6). N.B.: Two of the sampled ampoules were damaged during handling. For these determinations, the ampoules were cut open at their half-body height and measurements were individually made at three separate locations on the "top T" (or upper) and "bottom B" (or lower) halves.

Page 15 of 32 
Figure 8. Distribution of range for $n=3$ measurements of outer diameter $D$ on the same NIST-3 ampoule, from 411 sampled ampoules.

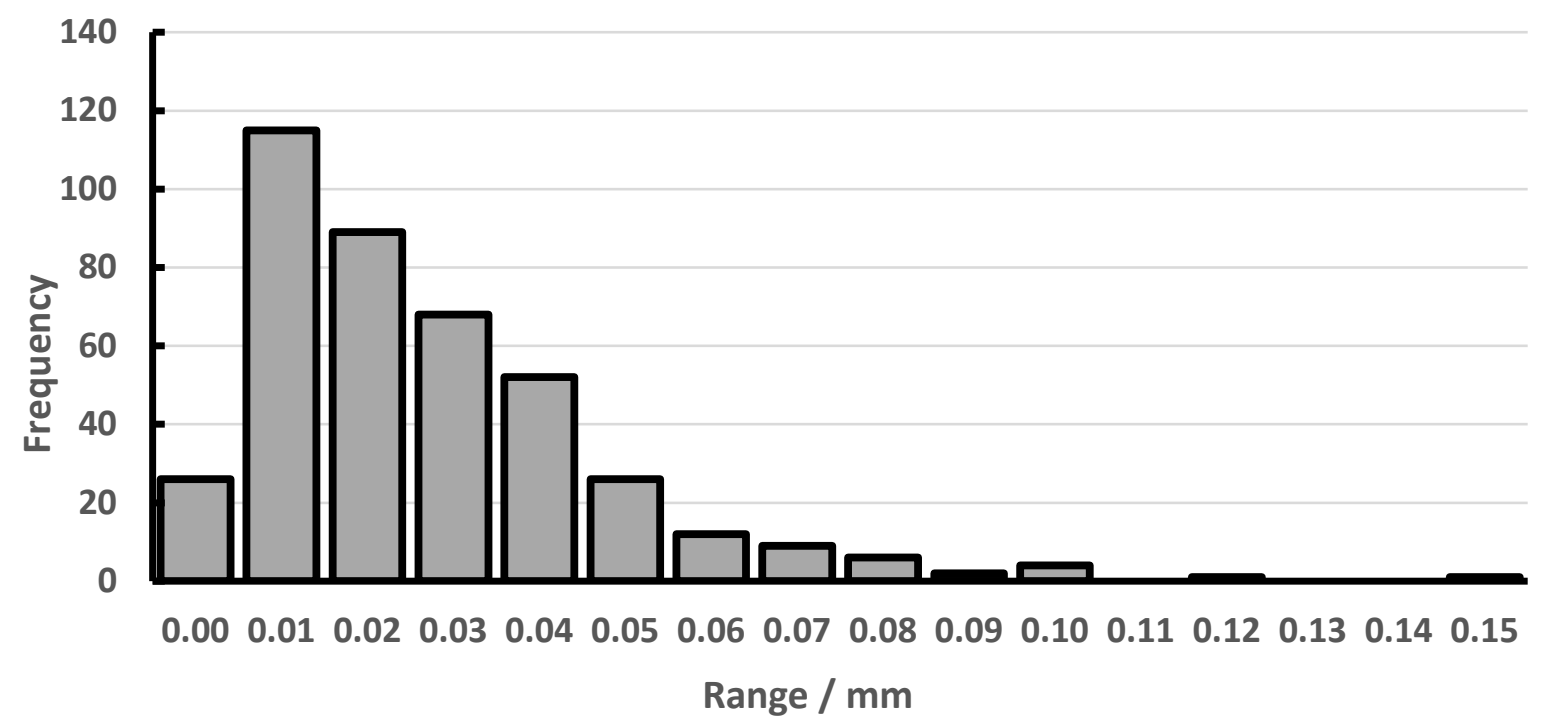

The outer diameter $D$ measurements on the 18 selected ampoules as a function of production order box number are shown in Figure 9 (upper trace). Each datum is the average of three measurements along both the upper and lower halves of the body wall. The overall mean diameter for the 108 measurements was $D=16.204$ $\mathrm{mm}$, with a standard deviation of $0.032 \mathrm{~mm}$. This is in agreement with the previous outer diameter determination $[D=(16.193 \pm 0.084) \mathrm{mm}]$, based on $n=1233$ measurements, to within $0.07 \%$. The middle trace of Figure 9 shows the ratio $D_{\mathrm{T}} / D_{\mathrm{B}}$ for the average of the 3 measurements on the upper half to the 3 measurements on the lower half for each ampoule. The mean radio was $D_{\mathrm{T}} / D_{\mathrm{B}}=1.0003$, with a standard deviation of 0.0016 . The outer diameter $D$ on these same identical 18 ampoules were previously measured (Figure 7), and the bottom trace of Figure 9 shows the ratio $D_{2} / D_{1}$ for the second determination $D_{2}$ compared to the first $D_{1}$, with a mean across the 18 ampoules of 1.0011 and standard deviation of 0.0023 .

Figure 10 shows the inner diameter $S$ measurements on the 18 selected ampoules as a function of production order box number (upper trace). As before, each datum is the average of three measurements of either the top half or bottom half of each ampoule. The mean and standard deviation on the $108 \mathrm{~S}$ determinations are $15.003 \mathrm{~mm}$ and $0.031 \mathrm{~mm}$, respectively. The lower trace gives the ratios $S_{T} / S_{B}$ for the top and bottom averages for the three measurements on each half of the cut ampoule. The mean ratio was $S_{T} / S_{B}=1.0003$ with a standard deviation of 0.0022 .

Body wall determinations on the 18 select ampoules were made by two methods, viz., (i) by direct caliper measurements $W$ on both halves of the cut ampoules and (ii) as obtained from outer and inner diameter measurements $\omega=(D-S) / 2$ from the averages of the cut ampoule halves. As before, each result is the average of three measurements on each half. The results for $W$ and $\omega$ are given in Figures 11 and 12, respectively. The mean value of $W$ from direct caliper measurements was $W=0.603 \mathrm{~mm}$ with a standard deviation for the 
distribution of $0.006 \mathrm{~mm}$, while that for $\omega$ from the derived $(D-S) / 2$ was $\omega=0.600 \mathrm{~mm}$ with a corresponding standard deviation of $0.019 \mathrm{~mm}$. The difference was $(\omega-W)=-0.003 \mathrm{~mm}$ with a standard deviation of 0.021 $\mathrm{mm}$.

Figure 9. Body wall outer diameter $D$ measurements for the NIST-3 ampoules on the 18 select ampoules (refer to Figure 6 ) as a function of production order box number. The middle trace gives the ratio $D_{\mathrm{T}} / D_{\mathrm{B}}$ of the measurements on the top and bottom of each ampoule half. The lower trace gives the ratio $D_{2} / D_{1}$ for the second to first determinations on the identical ampoules. Refer to text for details. In each trace, measurement the solid and dashed lines correspond, respectively, to the mean and the $95 \%$ confidence limits on the distribution of values

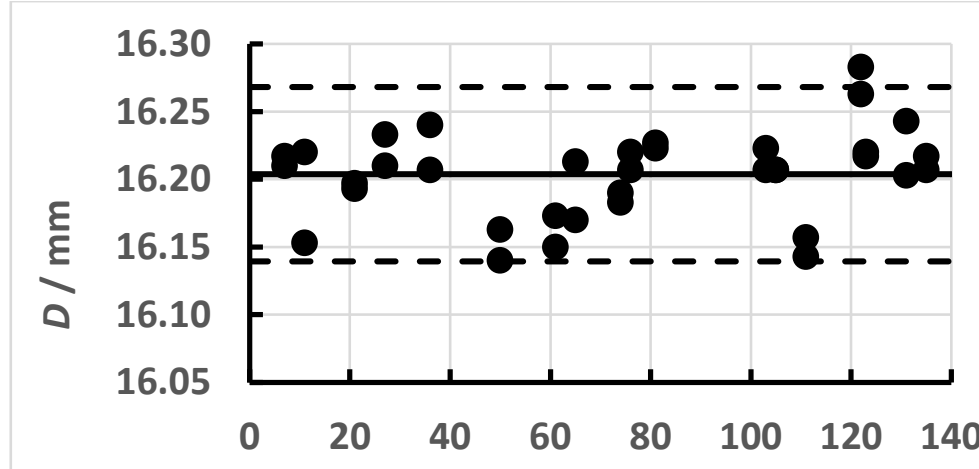

Box number
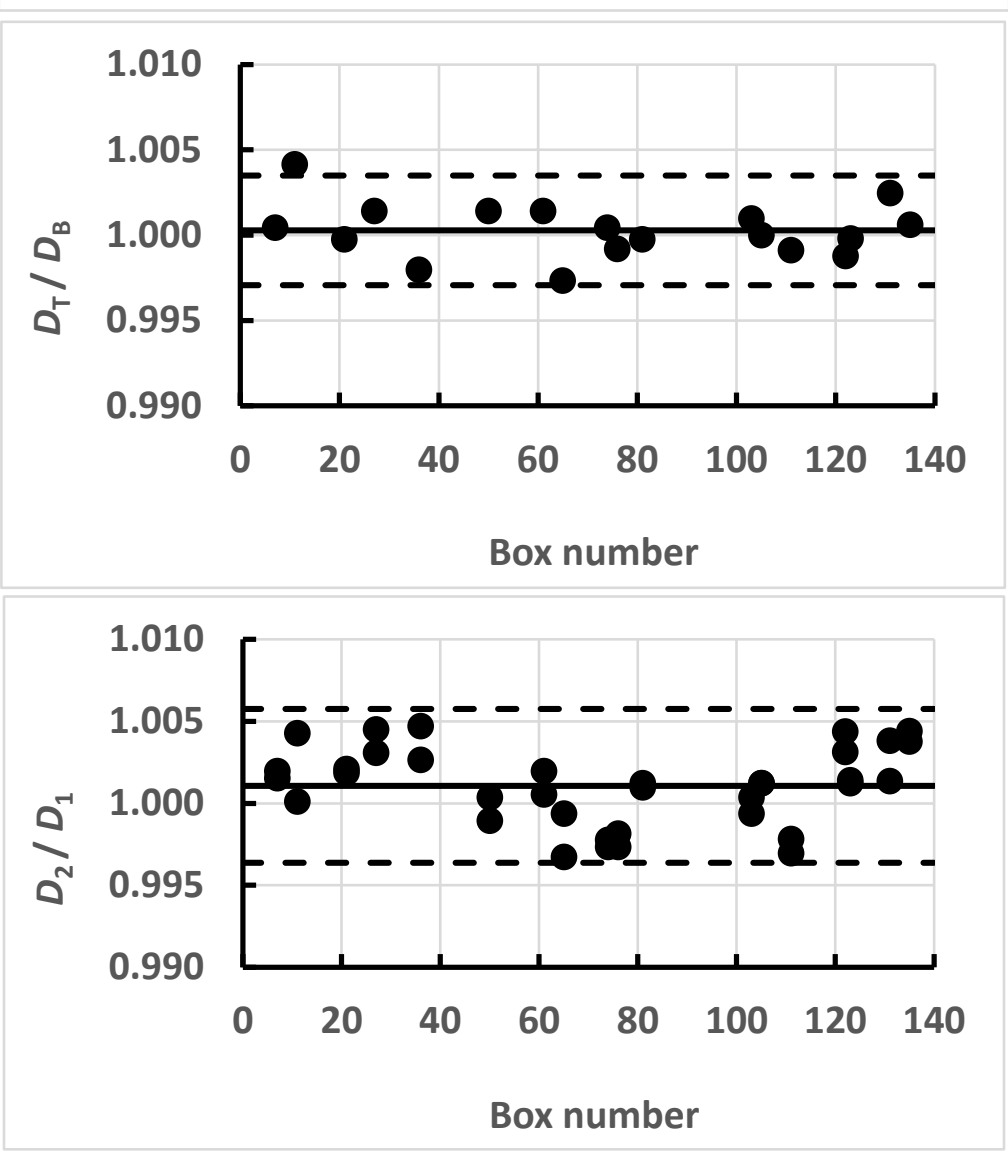

Page 17 of 32 
Figure 10. Body wall inner diameter $S$ measurements for the NIST-3 ampoules on the 18 select ampoules (refer to Figure 6 ) as a function of production order box number. The lower trace gives the ratio $S_{T} / S_{B}$ of the measurements on the top and bottom of each ampoule half. Refer to text for details. In each trace, measurement the solid and dashed lines correspond, respectively, to the mean and the $95 \%$ confidence limits on the distribution of values
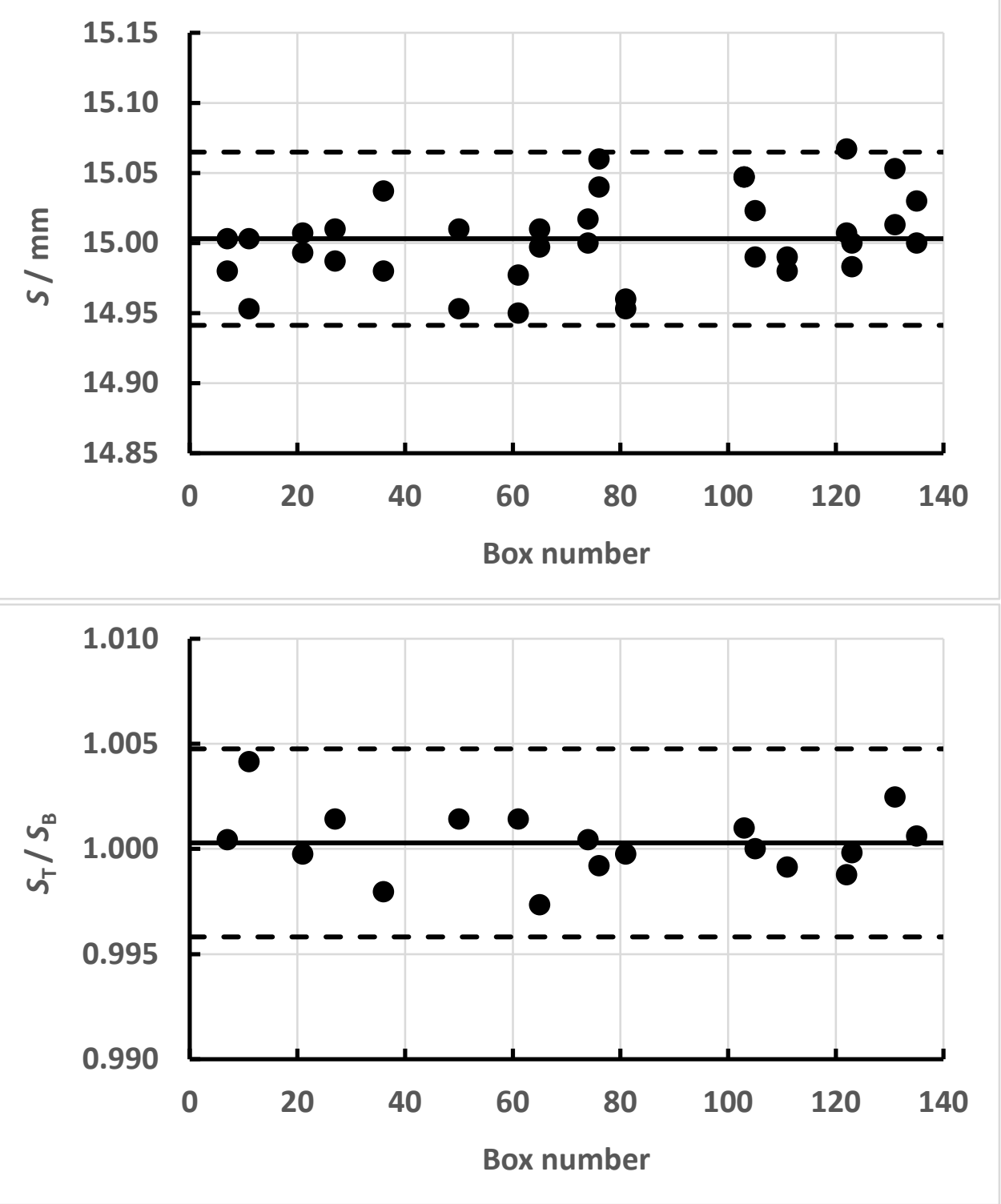
Figure 11. Body wall thickness $W$ for the NIST-3 ampoules by direct caliper measurement as a function of production order box number. Each datum represents the average of three measurements along the cut rim of the body wall on both the upper and lower halves. The lower trace shows the ratio $W_{T} / W_{B}$ of the averages for the top to bottom measurements for each ampoule. Refer to text for details. For each trace, the mean and $95 \%$ confidence limits on the distribution of values are shown with solid and dashed lines, respectively.

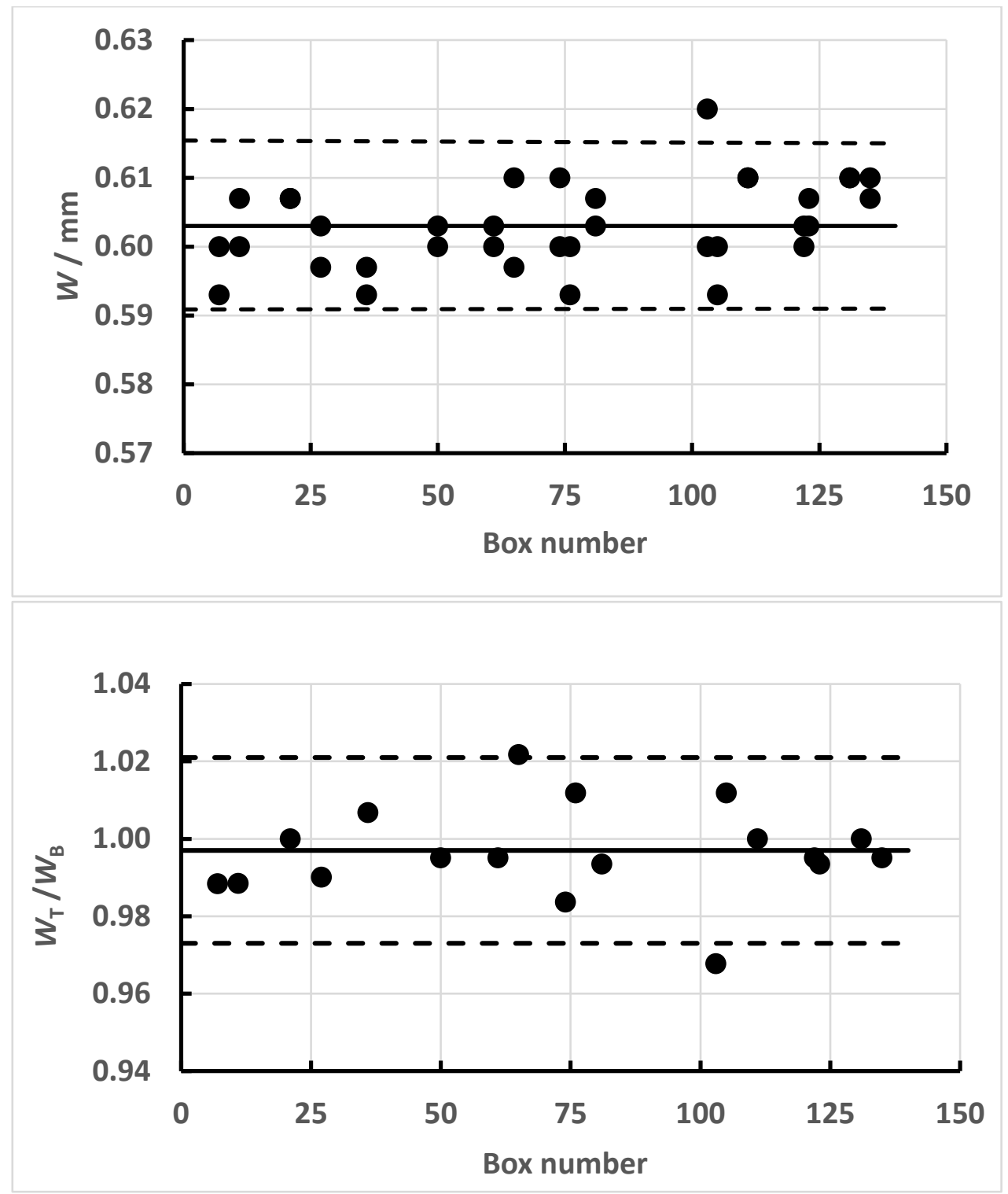

Page 19 of 32 
Figure 12. Body wall thickness $\omega$ for the NIST-3 ampoules as obtained from the outer and inner diameter measurements a function of production order box number. Each datum is the value of $\omega=(D-S) / 2$ as obtained from the average of the three measurements of $D$ and $S$ on both the upper and lower halves. The lower trace shows the difference $(\omega-W)$ for each ampoule. Refer to text for details. For each trace, the mean and $95 \%$ confidence limits on the distribution of values are shown with solid and dashed lines, respectively.
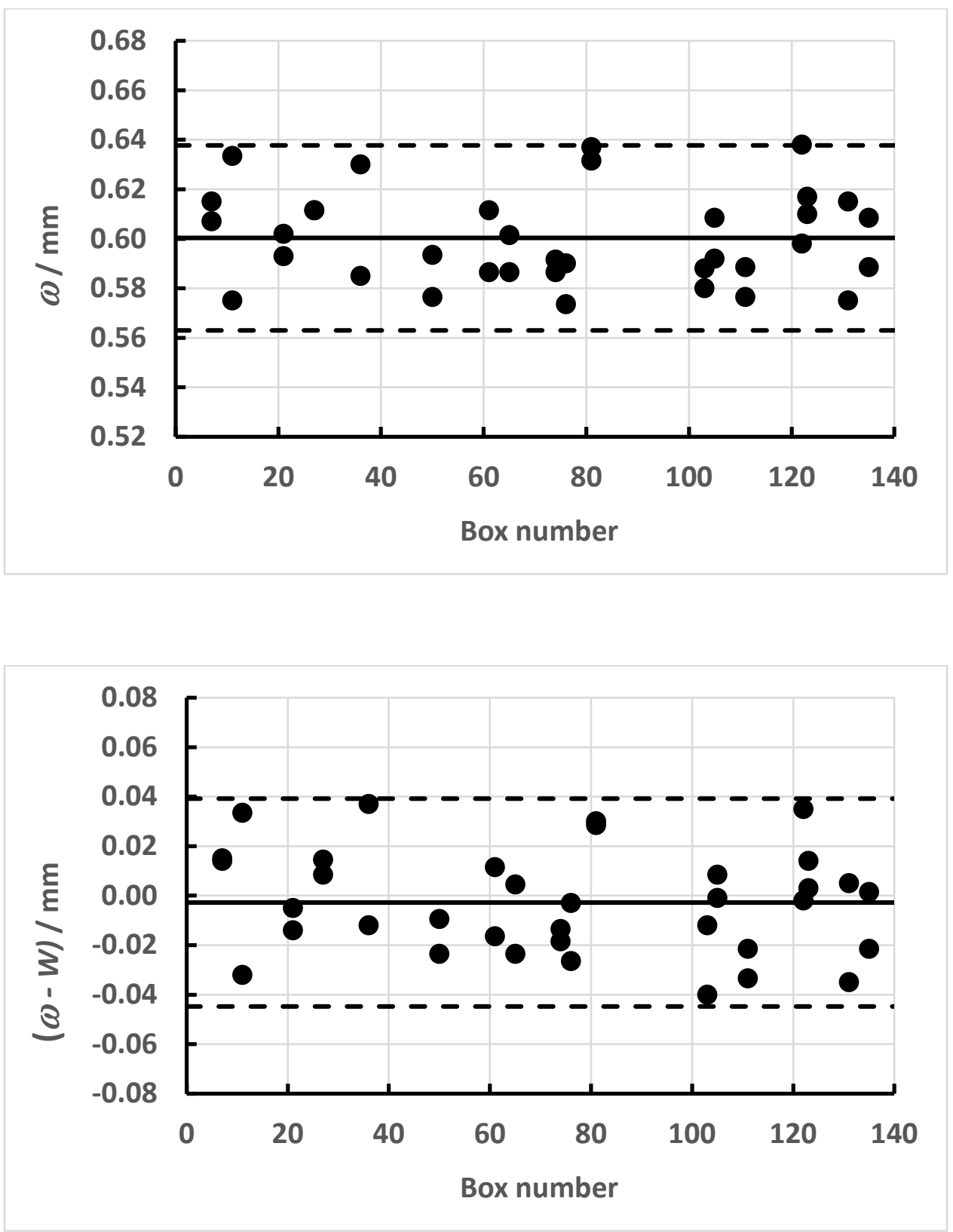
Measurement precision estimates for the determinations of the outer diameter $D$, inner diameter $S$, and wall thickness $W$ on the 18 selected ampoules, in terms of the range for $n=3$ measurements on each half of the same ampoule, are given in Figure 13.

It may be of interest to compare the dimensional measurements to the specifications requested by NIST and proposed by DWK for the NIST-3 ampoules, as shown in Figure 14.

Figure 13. Distributions for the range of $n=3$ measurements on the top and bottom halves of the same ampoule (for the 18 selected ampoules) for the outer diameter $D$ (upper trace), inner diameter $S$ (middle trace) and wall thickness $W$ (lower trace). Refer to text and Figures 9 through 12.

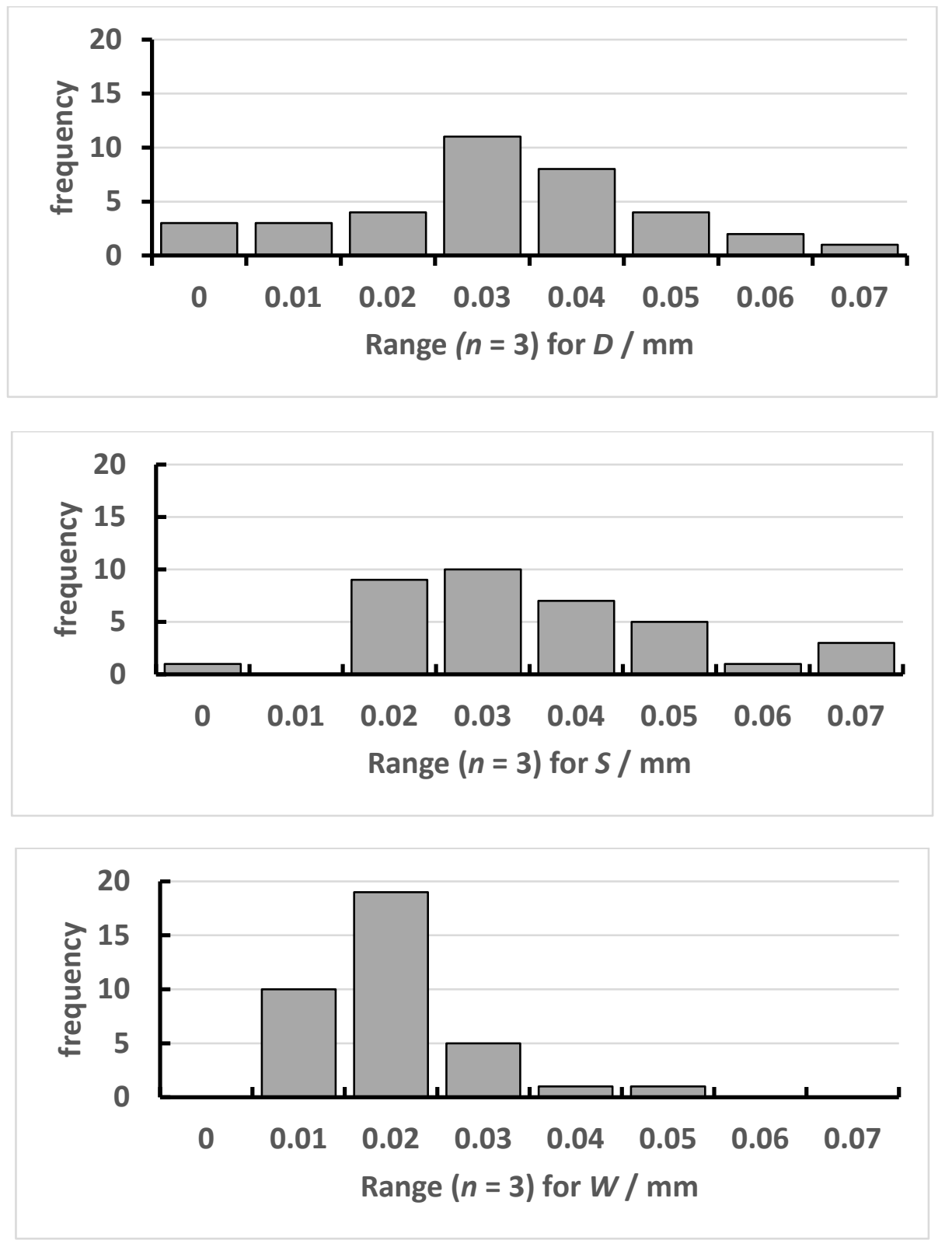

Page $\mathbf{2 1}$ of $\mathbf{3 2}$ 
Figure 14. Comparison of the caliper measurements of the body outer diameter $D$ and wall thickness $W$ for the NIST-3 ampoules to the specifications requested by NIST and specifications proposed by the DWK manufacturer. The limit intervals shown for the NIST and DWK specifications were unspecified but are presumed to be $>95 \%$ tolerance limits, while the NIST measurement intervals are $95 \%$ confidence limits.
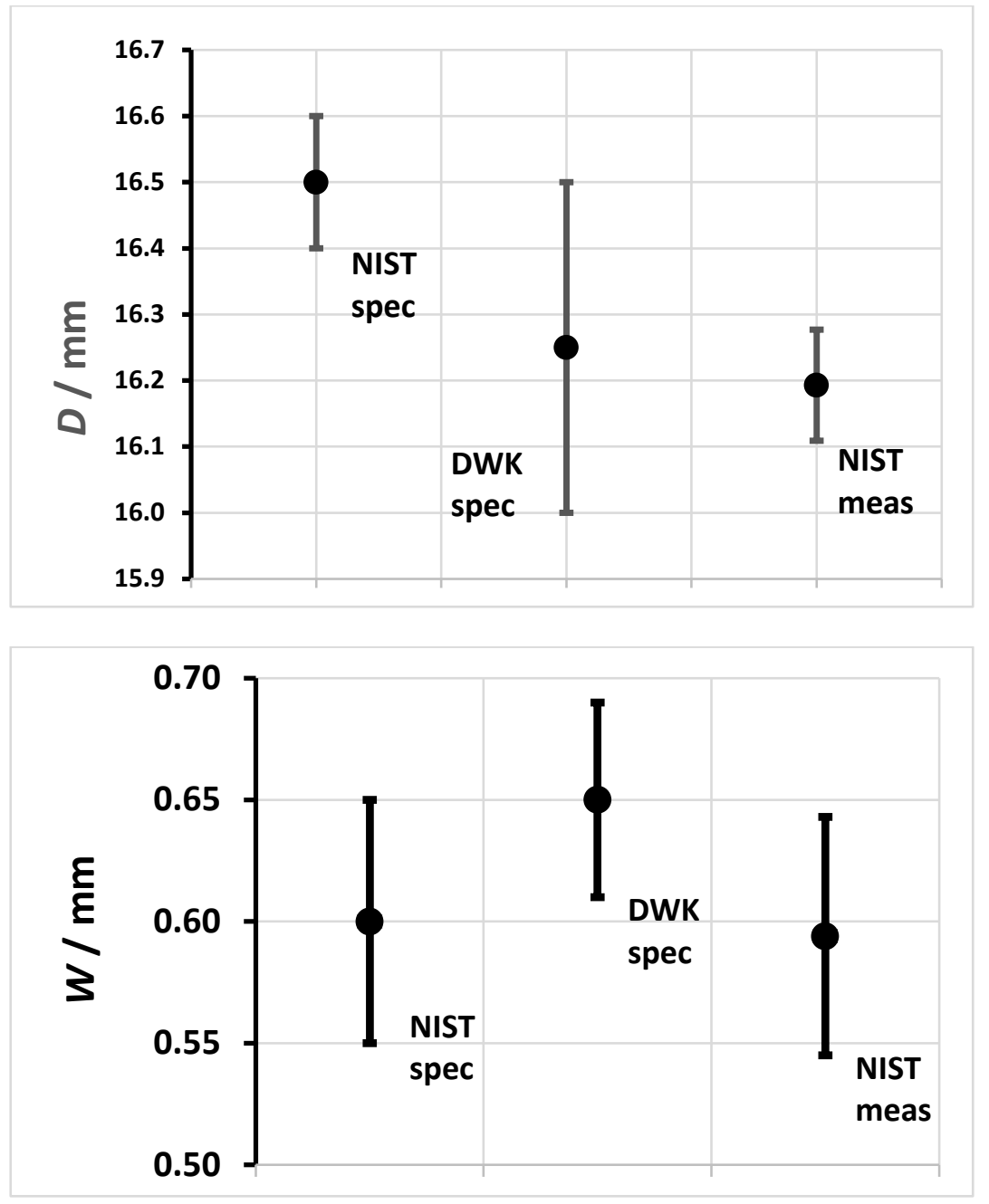

\section{NIST-3 TO NIST-1 COMPARISONS}

Of considerable interest, of course, is the difference between the NIST-1 and NIST-3 ampoules in terms of their respective effect on the response of various radionuclides in ionization chambers and for photonic emission spectrometry in fixed geometries.

Chemical analyses of the NIST-3 and NIST-1 ampoules with subsequent Monte Carlo modeling are being pursued. These results along with details for the photonic transmission comparisons (Tables 5 and 6 ) and future comparisons will be reported on separately. 
Some preliminary results for these initial comparisons in NIST ionization chambers are given in Table 5. Many more such comparisons are planned and will be continuing. The comparisons were made by filling the ampoules with $5 \mathrm{~mL}$ of the same radionuclidic solution, having an identical massic activity, and measuring the ionization current of each ampoule. As seen, it is apparent that the NIST-3 ampoules have a slightly higher response in ionization chambers, which may in some small part be attributed to the thinner wall thickness $W$ and smaller inner diameter $S$ in the NIST-3 ampoules. The differences between the NIST-1 and NIST-3 ampoules are $\Delta W=(0.039 \pm 0.017) \mathrm{mm}$ and $\Delta S=(0.133 \pm 0.017) \mathrm{mm}$ at $k=2$, which do not appear to be significant enough to produce the differences seen. More importantly, differences in the glass chemical composition, particularly for the heavy metal barium ( $\mathrm{Ba}, Z=56)$, may be a bigger factor. It may be recalled that the NIST specifications for the NIST-1 ampoules in 1976 requested that a "barium content of $2.25 \%$ would be preferable", in order to match the earlier NIST-0 ampoules. This and the likely lead ( $P b, Z=82)$ content in NIST1 ampoules is substantially greater than that in the NIST-3 ampoules (see Tables 2 and 3 ).

Table 5. Comparison of NIST-3 and NIST-1 ampoules in terms of the comparative response of various radionuclides in different ionization chambers and conditions, including the numbers of NIST-1 and NIST-3 ampoules used for the comparison. The uncertainty for the NIST-3/NIST-1 comparative response ratio is the computed $95 \%$ confidence interval for the ratio of the two ionization current means. Experimental details and discussion of these findings, in terms of chemical composition of ampoules and Monte Carlo modeling will be reported on separately.

\begin{tabular}{|c|c|c|c|c|}
\hline Nuclide & $\begin{array}{c}\text { Massic } \\
\text { activity level }\end{array}$ & $\begin{array}{l}\text { Solution } \\
\text { composition * }\end{array}$ & $\begin{array}{l}\text { Measurement method / } \\
\text { instrument / conditions }\end{array}$ & $\begin{array}{l}\text { NIST-3 / NIST-1 } \\
\text { Comparative } \\
\text { response }\end{array}$ \\
\hline${ }^{99} \mathrm{Mo}$ & $2.1 \mathrm{MBq} g-1$ & $\begin{array}{l}0.1 \mathrm{~mol} \cdot \mathrm{L}^{-1} \mathrm{NaOH} \\
0.0036 \% \mathrm{Na}_{2} \mathrm{MoO}_{4} \\
1.000 \mathrm{~g} \cdot \mathrm{mL}^{-1}\end{array}$ & $\begin{array}{l}\text { lonization chamber "A" } \\
5 \text { NIST-1 vs } 4 \text { NIST-3 ampoules }\end{array}$ & $1.00390 \pm 0.00042$ \\
\hline \multirow{2}{*}{${ }^{133} \mathrm{Ba}$} & \multirow{2}{*}{$380 \mathrm{kBq} \mathrm{g}^{-1}$} & \multirow{2}{*}{$\begin{array}{l}0.98 \mathrm{~mol} \cdot \mathrm{L}^{-1} \mathrm{HCL} \\
0.0088 \% \mathrm{Ba}^{+2} \\
1.015 \mathrm{~g} \cdot \mathrm{mL}^{-1}\end{array}$} & $\begin{array}{l}\text { Ionization chamber "A" } \\
3 \text { NIST-1 vs } 3 \text { NIST-3 ampoules }\end{array}$ & $1.00518 \pm 0.00042$ \\
\hline & & & $\begin{array}{l}\text { Ionization chamber "B" } \\
3 \text { NIST-1 vs } 3 \text { NIST-3 ampoules }\end{array}$ & $1.00642 \pm 0.00053$ \\
\hline \multirow{2}{*}{${ }^{241} \mathrm{Am}$} & \multirow{2}{*}{$10.5 \mathrm{kBq} \mathrm{g}^{-1}$} & \multirow{2}{*}{$\begin{array}{l}1.03 \mathrm{~mol} \cdot \mathrm{L}^{-1} \mathrm{HNO}_{3} \\
1.032 \mathrm{~g} \cdot \mathrm{mL}^{-1}\end{array}$} & $\begin{array}{l}\text { Ionization chamber "A" } \\
1 \text { NIST-1 vs } 1 \text { NIST-3 ampoule }\end{array}$ & $1.051 \pm 0.033$ \\
\hline & & & $\begin{array}{l}\text { Ionization chamber "B" } \\
1 \text { NIST-1 vs } 1 \text { NIST } 3 \text { ampoule }\end{array}$ & $1.045 \pm 0.034$ \\
\hline \multirow{2}{*}{${ }^{201} \mathrm{Tl}$} & \multirow{2}{*}{$2.1 \mathrm{MBq} \mathrm{g}^{-1}$} & \multirow{2}{*}{$\begin{array}{l}0.1 \mathrm{~mol} \cdot \mathrm{L}^{-1} \mathrm{HCl} \\
0.0053 \% \mathrm{Tl}^{+1} \\
1.001 \mathrm{~g} \cdot \mathrm{mL}^{-1}\end{array}$} & $\begin{array}{l}\text { Ionization chamber "A" } \\
4 \text { NIST-1 vs } 5 \text { NIST-3 ampoules }\end{array}$ & $1.0252 \pm 0.0022$ \\
\hline & & & $\begin{array}{l}\text { Ionization chamber "B" } \\
5 \text { NIST-1 vs } 5 \text { NIST } 3 \text { ampoules }\end{array}$ & $1.0243 \pm 0.0038$ \\
\hline${ }^{67} \mathrm{Ga}$ & $1.3 \mathrm{MBq} \mathrm{g}^{-1}$ & $\begin{array}{l}0.1 \mathrm{~mol} \cdot \mathrm{L}^{-1} \mathrm{HCl} \\
0.0052 \% \mathrm{Ga}^{+3}\end{array}$ & $\begin{array}{l}\text { Ionization chamber "B" } \\
3 \text { NIST-1 vs } 3 \text { NIST } 3 \text { ampoules }\end{array}$ & $1.00788 \pm 0.00013$ \\
\hline
\end{tabular}

${ }^{*}$ Concentrations are in mass percentage 


\section{(ii) By gamma-ray spectrometry}

Preliminary results for gamma-ray spectrometric comparisons of the NIST-1 and NIST-3 ampoules for detection of specific gamma rays in various radionuclides are given in Table 6. Each comparison was made with one NIST3 and one NIST-1 ampoule, each filled with $5 \mathrm{~mL}$ of the same radionuclidic solution having an identical massic activity. The comparisons are reported in terms of the ratio of detection efficiencies (for different detectors in fixed geometries) for the gamma rays emitted for the given radionuclide. Measurements were made in two main solid angle geometries; viz., the detectors viewing the ampoules through the bottoms or at the side of the ampoule body wall at various distances. The ratios are the averages of either bottom or side views of several detectors and geometries for each gamma ray.

The higher response with NIST-3 ampoules compared to NIST-1 ampoules as seen in the ionization chamber data (Table 5) is not as consistently evident when looking at individual gamma rays. Nevertheless, based on the data shown in the lower trace of Figure 15, it seems evident that the NIST-3 ampoules exhibit greater attenuation through the bottoms than the NIST-1 ampoules do, implying that the NIST-3 ampoules have a thicker bottom covering of glass. Visual inspections however seem to indicate that the bottoms of the NIST-1 ampoules have slightly more "push up" and are more irregular than the bottoms of the NIST-3 ampoules. The difference in side-geometry measurements is more inconsistent, as seen in the upper trace of Figure 15, with a slight positive bias for the NIST-3 ampoules. There is also no apparent difference in attenuation as a function of gamma-ray energy for either ampoule.

When considering the difference between the ionization chamber measurements (Table 5) and the gammaray spectrometry (Table 6 ) it is important to appreciate that the respective measurements are detecting very different quantities. The ionization chamber response includes not only the ionization resulting from all of the photons emitted from the specific radionuclide, but also detects other events and interactions, like Comptonscattered photons, low-energy $x$ rays from internal conversion, bremsstrahlung from beta or positron decay, fluorescent $x$ rays (e.g., of heavy metals like $\mathrm{Ba}$ ), etc. In contradistinction, the spectrometry results largely record only the full energy photopeak of the specific gamma ray.

Table 6 (follows). Comparison of the NIST-3 and NIST-1 ampoules in terms of their respective comparative effect for various radionuclides by gamma-ray spectrometry. The comparisons are reported in terms of the ratio of the detection efficiencies for specific gamma rays for each radionuclide. The ratios are the averages of several detectors and geometries for each line. The cited uncertainty for each ratio is an assumed $95 \%$ confidence interval using a coverage factor of $k=2$. The measurement conditions provide the NIST detectors used and geometries, as described previously (Pibida, et al., 2007; Pibida, et al., 2006). 
Table 6. (caption above)

\begin{tabular}{|c|c|c|c|c|c|}
\hline Nuclide & $\begin{array}{c}\text { Massic activity } \\
\text { level }\end{array}$ & $\begin{array}{l}\text { Solution } \\
\text { composition }\end{array}$ & NIST detectors and geometries & $\begin{array}{c}\text { Gamma-ray } \\
\text { energy }\end{array}$ & $\begin{array}{c}\text { NIST-3 / NIST-1 } \\
\text { Comparative response ratio }\end{array}$ \\
\hline \multirow{6}{*}{${ }^{133} \mathrm{Ba}$} & \multirow{6}{*}{$0.38 \mathrm{MBq} \cdot \mathrm{g}^{-1}$} & \multirow{6}{*}{$\begin{array}{l}0.98 \mathrm{~mol}^{-\mathrm{L}^{-1} \mathrm{HCL}} \\
88 \mu \mathrm{g} \mathrm{Ba}^{+2} \text { per gram } \\
\text { of solution } \\
1.015 \mathrm{~g} \cdot \mathrm{mL}^{-1}\end{array}$} & \multirow{6}{*}{$\begin{array}{l}\text { T-detector, } 90 \mathrm{~cm} \\
\text { G-detector, } 90 \mathrm{~cm} \\
\text { B detector }(1 \mathrm{~m}) \\
\text { N-detector, side }(1.5 \mathrm{~m})\end{array}$} & $53.2 \mathrm{keV}$ & $\begin{array}{c}1.000 \pm 0.012 \text { (bottom) } \\
1.0285 \pm 0.0049 \text { (side) }\end{array}$ \\
\hline & & & & $81.0 \mathrm{keV}$ & $\begin{array}{c}0.9889 \pm 0.0022 \text { (bottom) } \\
0.9964 \pm 0.0011 \text { (side) }\end{array}$ \\
\hline & & & & $276 \mathrm{keV}$ & $\begin{array}{c}0.9835 \pm 0.0043 \text { (bottom) } \\
0.9997 \pm 0.0030 \text { (side) }\end{array}$ \\
\hline & & & & $303 \mathrm{keV}$ & $\begin{array}{c}0.9830 \pm 0.0027 \text { (bottom) } \\
0.9993 \pm 0.0018 \text { (side) }\end{array}$ \\
\hline & & & & $356 \mathrm{keV}$ & $\begin{array}{c}0.9830 \pm 0.0021 \text { (bottom) } \\
0.9958 \pm 0.0011 \text { (side) }\end{array}$ \\
\hline & & & & $383 \mathrm{keV}$ & $\begin{array}{c}0.9834 \pm 0.0033 \text { (bottom) } \\
1.0018 \pm 0.0024 \text { (side) }\end{array}$ \\
\hline \multirow{5}{*}{${ }^{99} \mathrm{Mo}$} & \multirow{5}{*}{$2.1 \mathrm{MBq} \cdot \mathrm{g}^{-1}$} & \multirow{5}{*}{$\begin{array}{l}0.1 \mathrm{~mol} \cdot \mathrm{L}^{-1} \mathrm{NaOH} \\
36 \mu \mathrm{g} \mathrm{Na} \mathrm{MoO}_{4} \text { per } \\
\text { gram of solution } \\
1.000 \mathrm{~g} \cdot \mathrm{mL}^{-1}\end{array}$} & \multirow{5}{*}{$\begin{array}{l}\text { T-detector, } 45 \mathrm{~cm} \& \text { side }(10 \mathrm{~cm}) \\
\text { X-detector, } 40 \mathrm{~cm} \\
\text { G-detector, } 40 \mathrm{~cm} \& \text { side }(14 \mathrm{~cm}) \\
\text { B detector }(1 \mathrm{~m})\end{array}$} & $141 \mathrm{keV}$ & $\begin{array}{c}0.9829 \pm 0.0017 \text { (bottom) } \\
1.0068 \pm 0.0054 \text { (side) }\end{array}$ \\
\hline & & & & $181 \mathrm{keV}$ & $\begin{array}{c}0.9843 \pm 0.0038 \text { (bottom) } \\
1.0046 \pm 0.0055 \text { (side) }\end{array}$ \\
\hline & & & & $366 \mathrm{keV}$ & $\begin{array}{c}0.9914 \pm 0.0139 \text { (bottom) } \\
1.0055 \pm 0.0069 \text { (side) }\end{array}$ \\
\hline & & & & $740 \mathrm{keV}$ & $\begin{array}{c}0.9899 \pm 0.0046 \text { (bottom) } \\
1.0024 \pm 0.0058 \text { (side) }\end{array}$ \\
\hline & & & & $778 \mathrm{keV}$ & $\begin{array}{c}0.9906 \pm 0.0077 \text { (bottom) } \\
1.0039 \pm 0.0058 \text { (side) }\end{array}$ \\
\hline \multirow{2}{*}{${ }^{201} \mathrm{Tl}$} & \multirow{2}{*}{$2.1 \mathrm{MBq} \cdot \mathrm{g}^{-1}$} & \multirow{2}{*}{ 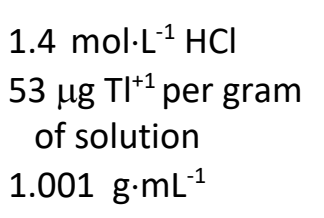 } & \multirow{2}{*}{$\begin{array}{l}\text { T-detector, } 45 \mathrm{~cm} \& \text { side }(10 \mathrm{~cm}) \\
\text { X-detector, } 40 \mathrm{~cm} \\
\text { G-detector, } 40 \mathrm{~cm} \& \text { side }(14 \mathrm{~cm})\end{array}$} & $135 \mathrm{keV}$ & $\begin{array}{c}0.9882 \pm 0.0041 \text { (bottom) } \\
0.9905 \pm 0.0075 \text { (side) }\end{array}$ \\
\hline & & & & $167 \mathrm{keV}$ & $\begin{array}{c}0.9835 \pm 0.0035 \text { (bottom) } \\
0.9945 \pm 0.0074 \text { (side) }\end{array}$ \\
\hline
\end{tabular}


Table 6. (cont.)

\begin{tabular}{|c|c|c|c|c|c|}
\hline Nuclide & $\begin{array}{c}\text { Massic activity } \\
\text { level }\end{array}$ & $\begin{array}{l}\text { Solution } \\
\text { composition }\end{array}$ & NIST detectors and geometries & $\begin{array}{l}\text { Gamma-ray } \\
\text { energy }\end{array}$ & $\begin{array}{c}\text { NIST-3 / NIST-1 } \\
\text { Comparative response ratio }\end{array}$ \\
\hline${ }^{241} \mathrm{Am}$ & $10.5 \mathrm{kBq} \cdot \mathrm{g}^{-1}$ & $\begin{array}{c}1.03 \mathrm{~mol} \cdot \mathrm{L}^{-1} \mathrm{HNO}_{3} \\
1.032 \mathrm{~g} \cdot \mathrm{mL}^{-1}\end{array}$ & $\begin{array}{l}\text { T-detector, } 25 \mathrm{~cm} \& \text { side }(10 \mathrm{~cm}) \\
\text { X-detector, } 25 \mathrm{~cm} \text { \& side }(10 \mathrm{~cm}) \\
\text { G-detector, } 20 \mathrm{~cm} \& \text { side }(14 \mathrm{~cm}) \\
\text { B detector, } 35 \mathrm{~cm}\end{array}$ & $59.5 \mathrm{keV}$ & $\begin{array}{l}0.987 \pm 0.012 \text { (bottom) } \\
1.010 \pm 0.011 \text { (side }\end{array}$ \\
\hline \multirow{5}{*}{${ }^{67} \mathrm{Ga}$} & \multirow{5}{*}{$1.3 \mathrm{MBq} \cdot \mathrm{g}^{-1}$} & \multirow{5}{*}{$\begin{array}{l}0.1 \mathrm{~mol} \cdot \mathrm{L}^{-1} \mathrm{HCl} \\
52 \mu \mathrm{g} \mathrm{Ga}{ }^{+3} \mathrm{per} \\
\text { gram of solution }\end{array}$} & \multirow{5}{*}{$\begin{array}{l}\text { T-detector, } 40 \mathrm{~cm}, 90 \mathrm{~cm} \mathrm{\&} \\
\quad \text { side }(10 \mathrm{~cm}) \\
\text { X-detector, } 40 \mathrm{~cm} \& \text { side }(10 \mathrm{~cm}) \\
\text { G-detector, } 40 \mathrm{~cm}, 90 \mathrm{~cm} \\
\& \text { side }(14 \mathrm{~cm})\end{array}$} & $93.3 \mathrm{keV}$ & $\begin{array}{c}0.989 \pm 0.010 \text { (bottom) } \\
1.013 \pm 0.014 \text { (side) }\end{array}$ \\
\hline & & & & $184 \mathrm{keV}$ & $\begin{array}{c}0.985 \pm 0.010 \text { (bottom) } \\
1.005 \pm 0.014 \text { (side) }\end{array}$ \\
\hline & & & & $209 \mathrm{keV}$ & $\begin{array}{c}0.979 \pm 0.012 \text { (bottom) } \\
1.007 \pm 0.016 \text { (side) }\end{array}$ \\
\hline & & & & $300 \mathrm{keV}$ & $\begin{array}{c}0.988 \pm 0.010 \text { (bottom) } \\
1.003 \pm 0.014 \text { (side) }\end{array}$ \\
\hline & & & & $393 \mathrm{keV}$ & $\begin{array}{c}0.986 \pm 0.013 \text { (bottom) } \\
1.002 \pm 0.015 \text { (side) }\end{array}$ \\
\hline
\end{tabular}


Figure 15. Comparative effect of the NIST-3 to NIST-1 ampoules, in terms of the efficiency ratio $R$ for specific gamma rays as a function of the energy $E$ in $\mathrm{keV}$, using the data given in Table 6 . The uncertainty bars on each ratio is an assumed $95 \%$ confidence interval using a coverage factor of $k=2$. The lower trace is that for a solid angle geometry where the ampoule is located above the detector such that the attenuation occurs through the ampoule bottom. The upper trace is for the condition where the detector views the ampoule through the side of the ampoule's body wall.
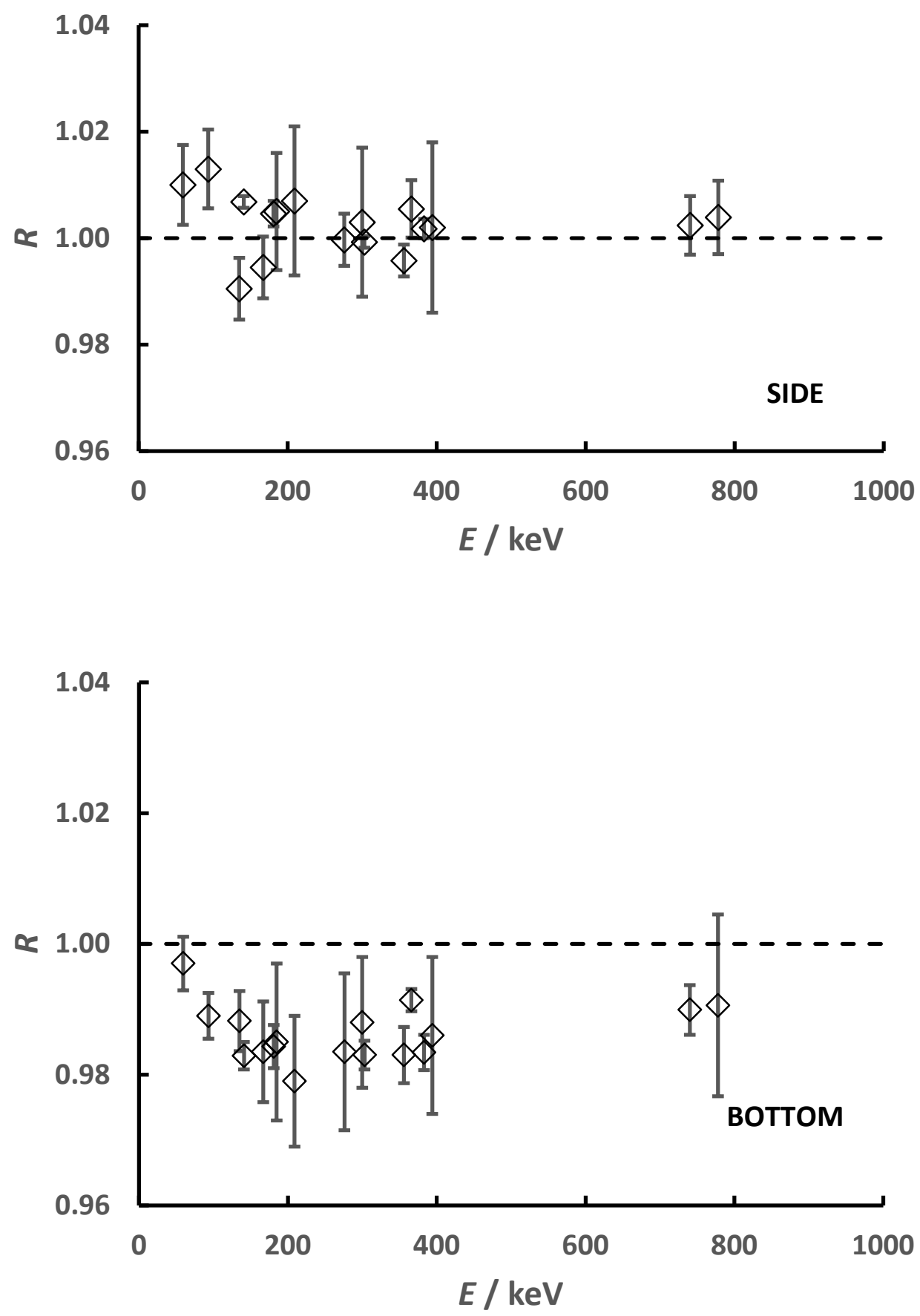

Page $\mathbf{2 7}$ of $\mathbf{3 2}$ 


\section{OTHER CONSIDERATIONS OF NIST-3 AMPOULES}

\section{(i) Glass density}

The density of borosilicate glass is reported to be $2.23 \mathrm{~g} \cdot \mathrm{cm}^{-3}$ at $25{ }^{\circ} \mathrm{C}$, and has a very low thermal expansion coefficient of approximately $3 \cdot 10^{-6} \mathrm{~K}^{-1}$ (Schott, 2019). Three independent determinations of the glass density for the NIST-3 ampoules were made by using Archimedean displacement of weighed quantities of NIST-3 glass shards in water. The density was found to be $(2.22 \pm 0.04) \mathrm{g} \cdot \mathrm{mL}^{-1}$ at $22{ }^{\circ} \mathrm{C}$ (at an assumed $k=2,95 \%$ confidence interval).

\section{(ii) Overpressure of sealed ampoules}

In recent years, as a result of reported incidents, there has been considerable concern over the possible overpressure of sealed ampoules containing high-level-activity solutions of alpha-emitting solutions, resulting in subsequent ampoule ruptures or explosions that are believed to derive from the radiolysis of water or buildup of He. Such concerns have been considered for over 50 years (BIPM, 1975). Although the NIST-3 ampoules have slightly thinner body wall by approximately $0.04 \mathrm{~mm}$ compared to NIST-1 ampoules, it is not considered significant enough to exacerbate the concern. Moreover, the substantially decreased age of the NIST-3 ampoules (2018 compared to 1976) is likely to decrease concern. Assuming that the site of an ampoule failure is at the tubular body wall and in the absence of major microcracks, the NIST-3 ampoule walls can be expected to withstand a maximum working pressure of about $500 \mathrm{kPa}$ to $800 \mathrm{kPa}$ based on the burst pressure calculations for borosilicate glass tubing (Geordi, 2019; Schott, 2019; Ace, 2019) -- with a "theoretical bursting pressure" about 4 to 5 times larger. Another scenario is that any ampoule rupture due to pressure build up would occur in the ampoule neck above the solution. Assuming a wall thickness at the neck of $0.4 \mathrm{~mm}$ and an inner diameter of $5.8 \mathrm{~mm}$ for the stem, the ampoule should withstand a pressure of $950 \mathrm{kPa}$ (Ace, 2019). These results are believed to be overly optimistic. However, it is widely reported that typical laboratory-grade borosilicate glassware can withstand pressures of $200 \mathrm{kPa}$ to $300 \mathrm{kPa}$ (Ace, 2019). Glass aging will of necessity decrease all estimates.

\section{(iii) Neck constriction}

A second concern that has emerged is that the smaller constriction at the ampoule neck (separating the ampoule body from the stem) for the NIST-3 ampoules makes it imperative that users ensure that solutions are completely drained from the neck before initiating photonic emission measurements in fixed geometries or before opening the ampoule.

\section{(iv) Evaporation loss rates}

A further concern involves whether the shortened neck length for the NIST-3 ampoules would result in an increase in the potential solution evaporation during the time between filling and sealing or during sealing.

Experiments were performed to evaluate this. Six NIST-3 ampoules were filled with a nominal $5 \mathrm{~mL}$ of water and pre-weighed. Post-weight measurements were made as a function of time from filling to sealing. During the delay time the ampoules were capped in the standard procedure used by our laboratory. The measurements were made over a duration of three hours, although even for the largest production runs of 400 to 600 ampoules, the time from filling to sealing is never more than about two hours. The trial was conducted at a laboratory temperature of $22.5{ }^{\circ} \mathrm{C}$ and relative humidity of $R H=40 \%$. The functional form of 
the mass loss $\Delta m$ was approximately linear with a fitted function of $\Delta m=(\mathrm{d} m / \mathrm{d} t) t$, where the evaporation mass loss rate is $(\mathrm{d} m / \mathrm{d} t)$. The median $(\mathrm{d} m / \mathrm{d} t)$ across the six ampoules was $(\mathrm{d} m / \mathrm{d} t)=-0.42 \mathrm{mg} \cdot \mathrm{h}^{-1}$, with a range of $0.12 \mathrm{mg} \cdot \mathrm{h}^{-1}$. A second independent trial was performed with another six ampoules over a period of five hours at $(21 \pm 1){ }^{\circ} \mathrm{C}$ and $R H=53 \%$. The median evaporation mass loss rate for this second trial was $\mathrm{d} m / \mathrm{d} t=-$ $0.37 \mathrm{mg} \cdot \mathrm{h}^{-1}$, with a range of $0.05 \mathrm{mg} \cdot \mathrm{h}^{-1}$. A third trial evaluated the total solution evaporation loss over a period of 114 hours. In this case, the median evaporation mass loss rate was $\mathrm{dm} / \mathrm{d} t=-0.44 \mathrm{mg} \cdot \mathrm{h}^{-1}$, with a range of $0.04 \mathrm{mg} \cdot \mathrm{h}^{-1}$. The agreements amongst these initial trials was comforting. With a one hour delay, the evaporation mass loss is $<0.01 \%$ for a $5 \mathrm{~mL}$ filling. A fourth and final trial was performed to compare the evaporation rates with the NIST-3 ampoules to that for the NIST-1 and NIST-2 ampoules, under conditions of both leaving the ampoules uncapped and with caps. The earlier trials with the NIST-3 ampoules used the small "orange" caps with inner diameter of nominal $8 \mathrm{~mm}$. The larger "red" caps with inner diameter of nominal 10 $\mathrm{mm}$ are the only caps that accommodate the larger NIST-2 ampoules. The NIST-1 and NIST-3 ampoules normally use the smaller orange caps. The test was performed with three ampoules, each filled to a nominal 5 $\mathrm{mL}$ of water, under each uncapped and capped condition as given in Table 7. The evaporation rates were evaluated from mass differences after $2.23 \mathrm{~h}$, and after longer intervals of $97 \mathrm{~h}$ and $187 \mathrm{~h}$. In all cases, the ampoules were momentarily uncapped during mass measurements and then re-capped. As indicated in Table 3 , there are apparent differences in the evaporation rates between the uncapped and capped conditions for all ampoule types, as might be expected. Differences between ampoules are also apparent, but not as significant. It appears that the evaporation rate for NIST-3 ampoules is slightly less than that for the NIST-1 ampoules, which may possibly be attributed to the smaller constriction at the ampoule neck (as noted above). It also appears that the evaporation rates initially (e.g., after $2.23 \mathrm{~h}$ ) are larger than after longer intervals, which is likely to be the result of no disturbance of the ampoule, cap, or solution during these longer intervals and the resulting averaging out of the mass loss over that longer time interval.

\section{(v) Tip sealing}

The tip sealing procedure used for the flame sealing of the shortened height of the NIST-3 ampoules has an additional advantage in the quantitative gravimetric filling of ampoules. Only very small mass losses result from volatilization of the glass during the ampoule tip sealing, such that the mass differences between an un-sealed filled ampoule and sealed ampoule can be used to directly estimate the solution evaporation loss from the dispensing time to sealing time. Remeasurement of the sealed ampoule mass is also useful in verifying that the contained volume is not a blunder from weight readings or transcription errors. Two trials were conducted to evaluate the glass volatilization mass loss on tip sealing of NIST-3 ampoules and its use in estimating solution evaporation loss. In the first trial, six empty ampoules (each of about $4.05 \mathrm{~g}$ ) were pre-weighed and postweighed after sealing. The mean mass loss was $(0.47 \pm 0.04) \mathrm{mg}$, were the cited uncertainty is a $95 \%$ confidence interval. At the same time, six ampoules filled with $5 \mathrm{~mL}$ of water (each with a mass of about 9.04 g) were also pre-weighed and post-weighed after sealing. The time from filling to sealing was approximately $20 \mathrm{~min}$. The average mass loss in this case was $(0.58 \pm 0.04) \mathrm{mg}$. The difference in these two mass losses $[0.11$ $\pm 0.06) \mathrm{mg}$ ] can be taken as the mass loss of solution during sealing. Of course, it includes any evaporation loss from the time of filling to the initiation of flame sealing. For the second trial, the automatic sealer's dwell time was increased (and used a cooler torch flame) such that each ampoule was heated by the flame during sealing for $10 \mathrm{~s}$. In this case, the mass loss for the unfilled sealed ampoules was $(0.41 \pm 0.05) \mathrm{mg}$, and the mass loss for the water filled ampoules was $(0.50 \pm 0.08) \mathrm{mg}$. As before, the difference of $(0.09 \pm 0.07) \mathrm{mg}$ can be taken to 
estimate the solution mass loss from filling to sealing, including any evaporation loss before sealing that may in fact account for most of the loss. The agreement between the two trials is remarkable.

Table 7. Comparison of evaporation rates (in $\mathrm{mg} \cdot \mathrm{h}^{-1}$ ) for the NIST-3, NIST-2, and NIST-1 ampoules under various uncapped and capped conditions, in terms of the mean and standard deviation for the distribution as obtained from mass differences for $n=3$ ampoules under each condition. Values for the $90 \mathrm{~h}$ to $190 \mathrm{~h}$ evaporation rates were based on the aggregated $n=15$ measurements for evaporation intervals of $89.8 \mathrm{~h}$, $95.2 \mathrm{~h}, 97.4 \mathrm{~h}, 185 \mathrm{~h}$, and $187 \mathrm{~h}$ (3 ampoule each).

\begin{tabular}{|c|l|c|c|}
\hline \multirow{2}{*}{ Ampoule type } & \multicolumn{1}{|c|}{ Condition } & \multicolumn{2}{c|}{ Evaporation rate $\left(\mathrm{mg} \cdot \mathrm{h}^{-1}\right.$ ) } \\
\cline { 3 - 4 } & & over $2.23 \mathrm{~h}$ & over 90 $\mathrm{h}$ to $190 \mathrm{~h}$ \\
\hline \multirow{3}{*}{ NIST-3 } & uncapped & $1.10 \pm 0.05$ & $0.71 \pm 0.02$ \\
\cline { 2 - 4 } & small cap ("orange") & $0.35 \pm 0.01$ & $0.27 \pm 0.01$ \\
\cline { 2 - 4 } & large cap ("red") & $0.65 \pm 0.05$ & $0.42 \pm 0.01$ \\
\hline \multirow{2}{*}{ NIST-2 } & uncapped & $1.37 \pm 0.03$ & $0.89 \pm 0.02$ \\
\cline { 2 - 4 } & large cap ("red") & $0.40 \pm 0.11$ & $0.34 \pm 0.01$ \\
\hline \multirow{3}{*}{ NIST-1 } & uncapped & $0.98 \pm 0.03$ & $0.55 \pm 0.02$ \\
\cline { 2 - 4 } & small cap ("orange") & $0.54 \pm 0.06$ & $0.25 \pm 0.01$ \\
\cline { 2 - 4 } & large cap ("red") & $0.76 \pm 0.24$ & $0.33 \pm 0.03$ \\
\hline
\end{tabular}

\section{SUMMARY}

This paper is intended to document and archive the historical record for the acquisition and testing of standardized ampoules used by the NIST / NBS Radioactivity Group for the past 70 years. These ampoules were intended to contain $5 \mathrm{~mL}$ of solutions of radionuclides decaying with photonic emission. They were and are used for the production, calibration, and dissemination of SRMs, in establishing transfer standards, and for direct calibrations of solutions in standard geometries. The fifth and most recent batch of ampoules, designated as NIST-3 (c. 2018), has been characterized by dimensional measurements, homogeneity as a function of production order, and compared to NIST-1 (c. 1976) ampoules for differences in photonic transmission. The efficacy of these shortened-neck NIST-3 ampoules has been demonstrated by: (1) their dimensional similarity and comparable utility to the NIST-1 ampoules; (2) the acceptable evaporation rate loss between typical filling and sealing times; (3) the ability to verify solution mass in sealed ampoules because of the small glass volatilization mass loss with tip sealing; and (4) although the differences between the NIST-3 and NIST-1 ampoules for their respective effects on photonic emission detection by either ionization chamber measurements or gamma ray spectrometry are metrologically significant, they are not so great as to make the adoption of NIST-3 ampoules proscriptive. 


\section{REFERENCES}

Ace (2019), Ace Glass, Inc. Support , Nomogram of Allowable Pressures Chart, https://www.aceglass.com/dpro/kb article.php?ref=9220-UOAK-4219 (accessed 6 June, 2019). ; What pressure can borosilicate lab glass handle? ; https://www.aceglass.com/dpro/kb article.php?ref=9849-EPAB$\underline{3259}$ (accessed 6 June 2019).

BIPM (1975), Procedures for accurately diluting and dispensing radioactive solutions, Monographie BIPM-1, Bureau International des Poids et Mesures, 9.

https://www.bipm.org/utils/common/pdf/monographieRI/Monographie BIPM-1.pdf (accessed 6 June 2019).

Collé, R. (1976), personal notes and correspondence, NIST Radioactivity Group files labelled "1976 NIST-1 Ampoules."

Collé, R. (2018), personal notes and correspondence, NIST Radioactivity Group files labelled "2018 NIST-3 Ampoules."

Fitzgerald, R. (2012), NIST Ionization Chamber "A" Sample-Height Corrections, Journal of Research of the National institute of Standards and Technology, 117, 80-95;

https://nvlpubs.nist.gov/nistpubs/jres/117/jres.117.003.pdf (accessed 6 June 2019);

http://dx.doi.org/10.6028/jres.117.003 (accessed 6 June 2019).

Geordi (2019), Geordi Tube Pressure Estimator, https://www.geordi.com.au/Pressure\%20Calc.htm (accessed 6 June 2019).

NIST (2019), Physical Measurement Laboratory, Radiation Physics Division, Standard Reference Material Ampoule Specifications and Opening Procedure, https://www.nist.gov/pml/radiation-physics/ampoulespecifications-and-opening-procedure (accessed 6 June 2019).

NIST (2019be), National Institute of Standrads and Technology, Staistical Engineeering Division, Data Plot; https://www.itl.nist.gov/div898/software/dataplot/homepage.htm (accessed 6 June, 2019); eFITS, http://stat.nist.gov/ heckert/sed/dlmf/prob toolkit.htm (accessed 6 June 2019).

Pibida, L., Hsieh, E., Fuentes-Figueroa, A., Hammond, M.M., Karam, L. (2006), Software studies for germanium detector data analysis, Appl. Radiat. Isot. 64, 1313-1318;

https://www.sciencedirect.com/science/article/pii/S0969804306000893?via\%3Dihub (accessed 6 June 2019).

Pibida, L., Nafee, S.S., Unterweger, M., Hammond, M.M., Karam, L., Abbas, M.I. (2007), Calibration of HPGe gamma-ray detectors for measurement of radioactive noble gas sources, Appl. Radiat. Isot. 65, 225-233. https://ac.els-cdn.com/S096980430600251X/1-s2.0-S096980430600251X-main.pdf? tid=50ee02e1-c28f- 
46b0-b323-0d26b31cf7cd\&acdnat=1555440971 e49b22513af8980047e2e84efecc8132 (accessed 6 June 2019).

Ratel, G. (2007), The Système International de Référence and its application in key comparisons, Metrologia 44 (4), S7-S16. https://iopscience.iop.org/article/10.1088/0026-1394/44/4/S02/pdf (accessed 6 June 2019).

Ritz, A. (1978), International Coherence of Activity Measurements, International Environment 1, 15-18.

Schott (2019), Borosilicate Glass Properties, https://www.schott.com/d/tubing/9a0f5126-6e35-43bd-bf2a349912caf9f2/1.3/schott-algae-brochure-borosilicate.pdf (accessed 6 June 2019); Burst Pressure \& Fracture Mechanics of Technical Glass, https://www.us.schott.com/tubing/english/products/properties/burstpressure.html (accessed 6 June 2019).

\section{ACKNOWLEDGEMENTS}

The acquisition and evaluations of the NIST-1 and NIST-3 ampules would not have been possible without the dedicated efforts of my NBS mentor, Ms. Lucy Cavallo, in 1976 and my NIST protégé, Dr. Lizbeth LaureanoPerez, in 2018. In addition, the support and advice of Drs. Ryan Fitzgerald and Brian Zimmerman was instrumental in securing the replacement NIST-3 ampoules as well as for adoption of the new automated tipsealing method for ampoules of shortened height. Other colleagues made substantial contributions to the preliminary evaluations and comparisons of the NIST-1 and NIST-3 ampoules: viz., Dr. Leticia Pibida and Ms. Lynne King for performing the exhaustive gamma ray spectrometric analyses; Dr. Willie Regits and Ms. Khyra Neal for preparing most of the ampoules used for the comparisons and for making the ionization chamber measurements; and Dr. Lizbeth Laureano-Perez for advice on the NIST-3 ampoule procurement and help with initial acceptance inspections, particularly with the dimensional measurements. Their collective efforts are deeply appreciated. Dr. Fitzgerald is also independently thanked for the continual devil's advocacy of my work on this project and his critical vetting of my drafts of this report.

\footnotetext{
ABOUT THE AUTHOR.

Ronald Collé is an internationally-recognized specialist with over 45 years of experience in nuclear and radiochemistry, radionuclidic metrology, and the development of standards. He has been affiliated with NBS / NIST, in various capacities since 1974, primarily within the Radioactivity Group, mainly working on the development of measurement methodologies and standards for environmental radiation protection and surveillance, the nuclear power industry, homeland security and nuclear forensic interests, research applications in nuclear physics as well as geophysical and geochemical sciences, and both diagnostic and therapeutic nuclear medicine. Dr. Collé has been personally involved in the selection, procurement, and testing of standardized ampoules used for Radioactivity SRMs and secondary measurements, including those used for international comparisons, for all modern era (post 1976) ampoules.
} 